\title{
Duodenum-preserving pancreatic resection versus pancreaticoduodenectomy for chronic pancreatitis (Review)
}

\author{
Gurusamy KS, Lusuku C, Halkias C, Davidson BR
}

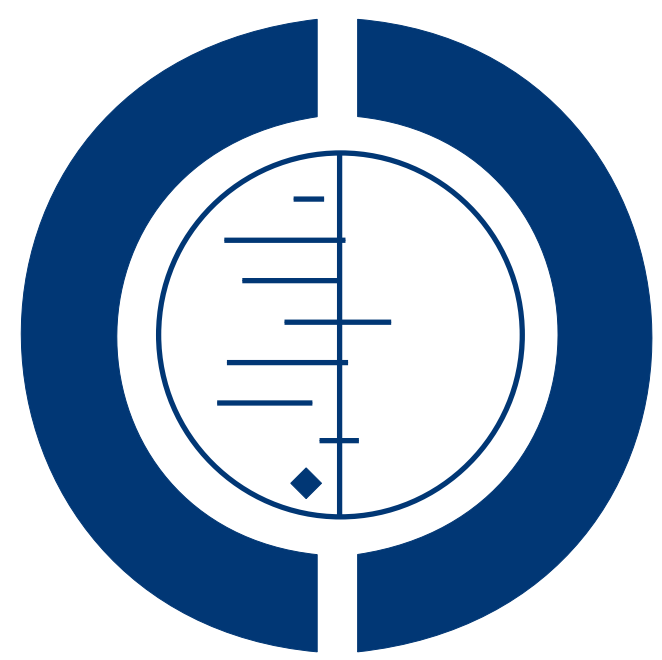

\section{THE COCHRANE COLLABORATION $^{\circledR}$}

This is a reprint of a Cochrane review, prepared and maintained by The Cochrane Collaboration and published in The Cochrane Library 2016, Issue 2

http://www.thecochranelibrary.com

\section{WILEY}

Duodenum-preserving pancreatic resection versus pancreaticoduodenectomy for chronic pancreatitis (Review)

Copyright () 2016 The Cochrane Collaboration. Published by John Wiley \& Sons, Ltd. 
TABLE OF CONTENTS

HEADER

ABSTRACT . . . . . . . . . . . . . . . . . . . . . . . . . . . . . . . . . . . . . . . . 1

PLAIN LANGUAGE SUMMARY . . . . . . . . . . . . . . . . . . . . . . . . . . . . . . . .

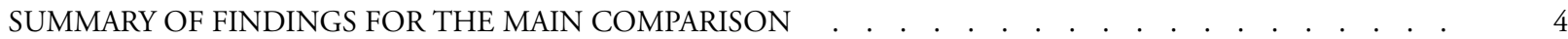

BACKGROUND . . . . . . . . . . . . . . . . . . . . . . . . . . . . . . . . . . . . . . . . . . 6

OBJECTIVES . . . . . . . . . . . . . . . . . . . . . . . . . . . . . . . . . . . . . . . . . . . . . . . . . .

METHODS . . . . . . . . . . . . . . . . . . . . . . . . . . . . . . . . . . . . . . 7

RESUlTS . . . . . . . . . . . . . . . . . . . . . . . . . . . . . . . . . . . . . . 11

Figure 1. . . . . . . . . . . . . . . . . . . . . . . . . . . . . . . . . . . . . . 12

Figure 2. . . . . . . . . . . . . . . . . . . . . . . . . . . . . . . . . . . . . . 13

Figure 3. . . . . . . . . . . . . . . . . . . . . . . . . . . . . . . . . . . . . . 14

ADDITIONAL SUMMARY OF FINDINGS . . . . . . . . . . . . . . . . . . . . . . . . . . . .

DISCUSSION . . . . . . . . . . . . . . . . . . . . . . . . . . . . . . . . . . . . . . . . .

AUTHORS' CONCLUSIONS . . . . . . . . . . . . . . . . . . . . . . . . . . . . . . . . . . . . .

ACKNOWLEDGEMENTS . . . . . . . . . . . . . . . . . . . . . . . . . . . . . . . . . . . . . . . .

REFERENCES . . . . . . . . . . . . . . . . . . . . . . . . . . . . . . . . . . . . . . 22

CHARACTERISTICS OF STUDIES . . . . . . . . . . . . . . . . . . . . . . . . . . . . . . 24

DATA AND ANALYSES . . . . . . . . . . . . . . . . . . . . . . . . . . . . . . . . . . . . . . . . . . . . . . . . .

Analysis 1.1. Comparison 1 Duodenum-preserving pancreatic resection versus pancreaticoduodenectomy, Outcome 1

Short-term mortality. . . . . . . . . . . . . . . . . . . . . . . . . . . . . . . .

Analysis 1.2. Comparison 1 Duodenum-preserving pancreatic resection versus pancreaticoduodenectomy, Outcome 2 Long-term mortality.

Analysis 1.4. Comparison 1 Duodenum-preserving pancreatic resection versus pancreaticoduodenectomy, Outcome 4 Quality of life (> 5 years).

Analysis 1.5. Comparison 1 Duodenum-preserving pancreatic resection versus pancreaticoduodenectomy, Outcome 5 Adverse events (proportion).

Analysis 1.6. Comparison 1 Duodenum-preserving pancreatic resection versus pancreaticoduodenectomy, Outcome 6 Adverse events (number of adverse events).

Analysis 1.8. Comparison 1 Duodenum-preserving pancreatic resection versus pancreaticoduodenectomy, Outcome 8 Employed.

Analysis 1.9. Comparison 1 Duodenum-preserving pancreatic resection versus pancreaticoduodenectomy, Outcome 9 New-onset diabetes.

Analysis 1.10. Comparison 1 Duodenum-preserving pancreatic resection versus pancreaticoduodenectomy, Outcome 10 Pancreatic exocrine insufficiency.

Analysis 2.1. Comparison 2 Duodenum-preserving pancreatic resection versus pancreaticoduodenectomy (subgroup analysis), Outcome 1 Short-term mortality.

Analysis 2.2. Comparison 2 Duodenum-preserving pancreatic resection versus pancreaticoduodenectomy (subgroup analysis), Outcome 2 Long-term mortality.

Analysis 2.4. Comparison 2 Duodenum-preserving pancreatic resection versus pancreaticoduodenectomy (subgroup analysis), Outcome 4 Quality of life (> 5 years).

APPENDICES

CONTRIBUTIONS OF AUTHORS

DECLARATIONS OF INTEREST

SOURCES OF SUPPORT

DIFFERENCES BETWEEN PROTOCOL AND REVIEW

Duodenum-preserving pancreatic resection versus pancreaticoduodenectomy for chronic pancreatitis (Review)

Copyright () 2016 The Cochrane Collaboration. Published by John Wiley \& Sons, Ltd. 


\title{
[Intervention Review] \\ Duodenum-preserving pancreatic resection versus pancreaticoduodenectomy for chronic pancreatitis
}

\author{
Kurinchi Selvan Gurusamy ${ }^{1}$, Charnelle Lusuku ${ }^{2}$, Constantine Halkias ${ }^{3}$, Brian R Davidson ${ }^{1}$ \\ ${ }^{1}$ Department of Surgery, Royal Free Campus, UCL Medical School, London, UK. ${ }^{2}$ School of Medicine, The University of Nottingham, \\ Nottingham, UK. ${ }^{3}$ Barking, Redbridge and Havering University Hospitals NHS Trust, Barts and the London School of Medicine and \\ Dentistry, London, UK \\ Contact address: Kurinchi Selvan Gurusamy, Department of Surgery, Royal Free Campus, UCL Medical School, Royal Free Hospital, \\ Rowland Hill Street, London, NW3 2PF, UK. k.gurusamy@ucl.ac.uk.
}

Editorial group: Cochrane Upper GI and Pancreatic Diseases Group.

Publication status and date: New, published in Issue 2, 2016.

Review content assessed as up-to-date: 22 June 2015.

Citation: Gurusamy KS, Lusuku C, Halkias C, Davidson BR. Duodenum-preserving pancreatic resection versus pancreaticoduodenectomy for chronic pancreatitis. Cochrane Database of Systematic Reviews 2016, Issue 2. Art. No.: CD011521. DOI: 10.1002/14651858.CD011521.pub2.

Copyright (C) 2016 The Cochrane Collaboration. Published by John Wiley \& Sons, Ltd.

\begin{abstract}
A B S T R A C T
Background

Surgical excision by removal of the head of the pancreas to decompress the obstructed ducts is one of the treatment options for people with symptomatic chronic pancreatitis. Surgical excision of the head of the pancreas can be performed by excision of the duodenum along with the head of the pancreas (pancreaticoduodenectomy (PD)) or without excision of the duodenum (duodenum-preserving pancreatic head resection (DPPHR)). There is currently no consensus on the method of pancreatic head resection in people with chronic pancreatitis.
\end{abstract}

Objectives

To assess the benefits and harms of duodenum-preserving pancreatic head resection versus pancreaticoduodenectomy in people with chronic pancreatitis for whom pancreatic resection is considered the main treatment option.

\section{Search methods}

We searched the Cochrane Central Register of Controlled Trials (CENTRAL), MEDLINE, EMBASE, Science Citation Index Expanded, and trials registers to June 2015 to identify randomised trials. We also searched the references of included trials to identify further trials.

\section{Selection criteria}

We considered only randomised controlled trials (RCT) performed in people with chronic pancreatitis undergoing pancreatic head resection, irrespective of language, blinding, or publication status, for inclusion in the review.

\section{Data collection and analysis}

Two review authors independently identified trials and extracted data. We calculated the risk ratio (RR), mean difference (MD), rate ratio $(\mathrm{RaR})$, or hazard ratio (HR) with $95 \%$ confidence intervals $(\mathrm{CI})$ based on an available-case analysis.

Duodenum-preserving pancreatic resection versus pancreaticoduodenectomy for chronic pancreatitis (Review)

Copyright (c) 2016 The Cochrane Collaboration. Published by John Wiley \& Sons, Ltd. 


\section{Main results}

Five trials including 292 participants met the inclusion criteria for the review. After exclusion of 23 participants mainly due to pancreatic cancer or because participants did not receive the planned treatment, a total of 269 participants (with symptomatic chronic pancreatitis involving the head of pancreas and requiring surgery) were randomly assigned to receive DPPHR (135 participants) or PD (134 participants). The trials did not report the American Society of Anesthesiologists (ASA) status of the participants. All the trials were single-centre trials and included people with and without obstructive jaundice and people with and without duodenal stenosis but did not report data separately for those with and without jaundice or those with and without duodenal stenosis. The surgical procedures compared in the five trials included DPPHR (Beger or Frey procedures, or wide local excision of the head of the pancreas) and PD (pylorus-preserving pancreaticoduodenectomy or Whipple procedure). The participants were followed up for various periods of time ranging from one to 15 years. The trials were at unclear or high risk of bias. The overall quality of evidence was low or very low.

The differences in short-term mortality (up to 90 days after surgery) (RR 2.89, 95\% CI 0.31 to 26.87; 369 participants; 5 studies; DPPHR: 2/135 (1.5\%) versus PD: 0/134 (0\%); very low quality evidence) or long-term mortality (maximal follow-up) (HR 0.65, $95 \%$ CI 0.31 to $1.34 ; 229$ participants; 4 studies; very low quality evidence), medium-term (three months to five years) (only a narrative summary was possible; 229 participants; 4 studies; very low quality evidence), or long-term quality of life (more than five years) (MD 8.45, 95\% CI -0.27 to 17.18; 101 participants; 2 studies; low quality evidence), proportion of people with adverse events (RR 0.55 , 95\% CI 0.22 to 1.35; 226 participants; 4 studies; DPPHR: 23/113 (adjusted proportion 20\%) versus PD: 41/113 (36.3\%); very low quality evidence), number of people with adverse events (RaR 0.95, 95\% CI 0.43 to 2.12; 43 participants; 1 study; DPPHR: $12 / 22$ (54.3 events per 100 participants) versus PD: 12/21 (57.1 events per 100 participants); very low quality evidence), proportion of people employed (maximal follow-up) (RR 1.54, 95\% CI 1.00 to 2.37; 189 participants; 4 studies; DPPHR: 65/98 (adjusted proportion 69.4\%) versus PD: 41/91 (45.1\%); low quality evidence), incidence proportion of diabetes mellitus (maximum follow-up) (RR 0.78, 95\% CI 0.50 to 1.22; 269 participants; 5 studies; DPPHR: 25/135 (adjusted proportion 18.6\%) versus PD: 32/134 (23.9\%); very low quality evidence), and prevalence proportion of pancreatic exocrine insufficiency (maximum follow-up) (RR $0.83,95 \%$ CI 0.68 to 1.02; 189 participants; 4 studies; DPPHR: 62/98 (adjusted proportion 62.0\%) versus PD: 68/91 (74.7\%); very low quality evidence) were imprecise. The length of hospital stay appeared to be lower with DPPHR compared to PD and ranged between a reduction of one day and five days in the trials (208 participants; 4 studies; low quality evidence). None of the trials reported short-term quality of life (four weeks to three months), clinically significant pancreatic fistulas, serious adverse events, time to return to normal activity, time to return to work, and pain scores using a visual analogue scale.

\section{Authors' conclusions}

Low quality evidence suggested that DPPHR may result in shorter hospital stay than PD. Based on low or very low quality evidence, there is currently no evidence of any difference in the mortality, adverse events, or quality of life between DPPHR and PD. However, the results were imprecise and further RCTs are required on this topic. Future RCTs comparing DPPHR with PD should report the severity as well as the incidence of postoperative complications and their impact on patient recovery. In such trials, participant and observer blinding should be performed and the analysis should be performed on an intention-to-treat basis to decrease the bias. In addition to the short-term benefits and harms such as mortality, surgery-related complications, quality of life, length of hospital stay, return to normal activity, and return to work, future trials should consider linkage of trial participants to health databases, social databases, and mortality registers to obtain the long-term benefits and harms of the different treatments.

\section{PLAIN LANGUAGE SUMMARY}

Duodenum-preserving pancreatic resection versus pancreaticoduodenectomy for chronic pancreatitis

\section{Review question}

Should the duodenum (upper part of the small intestine) be removed while removing the pancreatic head in people with symptoms of chronic pancreatitis?

\section{Background}

The pancreas is an organ in the belly (abdomen) that secretes several digestive enzymes into the pancreatic ductal system (tubes that carry the pancreatic juice secreted by the pancreatic cells), which empties into the small bowel. It also comprises the Islets of Langerhans, which secrete several hormones including insulin (helps regulate blood sugar). Chronic pancreatitis is long-standing and progressive inflammation of the pancreas resulting in destruction and replacement of pancreatic material (tissue) with fibrous tissue. This may 
lead to digestive enzyme deficiency (shortage) and insulin deficiency leading to diabetes (a lifelong condition that causes a person's blood sugar level to become too high). Alcohol is considered the main cause of acute pancreatitis. Chronic abdominal pain is the major symptom of chronic pancreatitis. The pain is usually in the upper abdomen and is described as deep, penetrating, and radiating to the back. Various theories exist about the reason for pain in chronic pancreatitis. One of the theories is that the disease process obstructs the pancreatic duct. So, surgery to remove the head of the pancreas (the part that is encircled by the duodenum) is recommended for some people with pain uncontrolled with medicines. Major complications of surgery include deaths (mortality) and re-operations. However, it is unclear whether the duodenum should be excised (surgically removed) along with the head of the pancreas. Thus, we searched for existing studies on the topic. We included all randomised controlled trials (clinical studies where people are randomly put into one of two or more treatment groups) whose results were reported to 22 June 2015.

\section{Study characteristics}

Five trials including 292 participants met the inclusion criteria for the review. After exclusion of 23 participants due to various reasons, 269 participants (with symptomatic chronic pancreatitis involving the head of pancreas and undergoing surgery) received duodenumpreserving pancreatic head resection (DPPHR) (head of pancreas is removed without removing the duodenum) (135 participants) or pancreaticoduodenectomy (PD) (head of pancreas is removed along with the duodenum encircling it) (134 participants) in these trials. The trials did not report anaesthetic risk (likelihood of complications due to anaesthesia) of the participants. All the trials were single-centre (occurred in only one clinical or medical centre). The participants were observed (followed up) for various periods of time ranging from one to 15 years. All the trials were at high risk of bias.

\section{Key results}

The differences in short-term (up to 90 days after surgery) or long-term (maximal follow-up) mortality, medium-term (three months to five years) or long-term (more than five years) quality of life, percentage and number of people with side effects, percentage of people employed (maximal follow-up), percentage of people who developed diabetes (maximum follow-up), and percentage of people with pancreatic digestive enzyme deficiency (maximum follow-up) were imprecise. The length of hospital stay appeared to be lower with DPPHR compared to PD and ranged between a reduction of one and five days in the trials. None of the trials reported short-term quality of life (four weeks to three months), clinically significant pancreatic fistulas (abnormal drainage of pancreatic juice internally or externally), serious side effects, time to return to normal activity, time to return to work, and pain scores using a visual analogue scale (a measurement tool to compare subjective measures such as pain that cannot be directly measured; pain levels between 0 and 10 or 0 and 100).

\section{Quality of the evidence}

The quality of evidence was low or very low. As a result, further studies are required on this topic. Such studies should report the severity of postoperative complications and their impact on patient recovery and should include all the trial participants in the results. In addition to the short-term benefits and harms such as mortality, surgery-related complications, quality of life, length of hospital stay, return to normal activity, and return to work, future trials should consider linkage of trial participants to health databases, social databases, and mortality registers to obtain the long-term benefits and harms of the different treatments.

Duodenum-preserving pancreatic resection versus pancreaticoduodenectomy for chronic pancreatitis (Review) 


\section{SUMMARY OF FINDINGS FOR THE MAIN COMPARISON [Explanation]}

Patient or population: people requiring surgery for chronic pancreatitis

Setting: surgical unit

Intervention: duodenum-preserving pancreatic resection

Comparison: pancreaticoduodenectomy

\begin{tabular}{|c|c|c|c|c|c|c|}
\hline \multirow[t]{2}{*}{ Outcomes } & \multicolumn{2}{|c|}{ Anticipated absolute effects* $(95 \%$ CI) } & \multirow{2}{*}{$\begin{array}{l}\text { Relative effect } \\
(95 \% \mathrm{CI})\end{array}$} & \multirow{2}{*}{$\begin{array}{l}\text { Number of participants } \\
\text { (studies) }\end{array}$} & \multirow{2}{*}{$\begin{array}{l}\text { Quality of the evidence } \\
\text { (GRADE) }\end{array}$} & \multirow[t]{2}{*}{ Comments } \\
\hline & $\begin{array}{l}\text { Risk with pancreatico- } \\
\text { duodenectomy }\end{array}$ & $\begin{array}{l}\text { Risk with duodenum- } \\
\text { preserving pancreatic } \\
\text { resection }\end{array}$ & & & & \\
\hline Short-term mortality & 10 per 1000 & $\begin{array}{l}29 \text { per } 1000 \\
(3 \text { to } 269)\end{array}$ & $\begin{array}{l}\text { RR } 2.89 \\
\text { (0.31 to 26.87) }\end{array}$ & $\begin{array}{l}269 \\
\text { (5 RCTs) }\end{array}$ & $\begin{array}{l}\oplus \bigcirc \bigcirc \bigcirc \\
\text { Very low }{ }^{1,2}\end{array}$ & - \\
\hline Long-term mortality & 281 per 1000 & $\begin{array}{l}193 \text { per } 1000 \\
(97 \text { to } 357)\end{array}$ & $\begin{array}{l}\text { HR } 0.65 \\
(0.31 \text { to } 1.34)\end{array}$ & $\begin{array}{l}229 \\
\text { (4 RCTs) }\end{array}$ & $\begin{array}{l}\oplus \bigcirc \bigcirc \bigcirc \\
\text { Very low }\end{array}$ & - \\
\hline Serious adverse events & - & - & - & - & - & $\begin{array}{l}\text { None of the included } \\
\text { studies reported seri- } \\
\text { ous adverse events. } \\
\text { Summary of findings } 2 \\
\text { summarises non-serious } \\
\text { adverse events }\end{array}$ \\
\hline $\begin{array}{l}\text { Quality of life ( } 3 \text { months } \\
\text { to } 5 \text { years) }\end{array}$ & $\begin{array}{l}\text { The median quality of life } \\
\text { ranged between } 28.6 \text { and } \\
67\end{array}$ & $\begin{array}{l}\text { The median quality of life } \\
\text { ranged between } 67 \text { and } \\
85.7\end{array}$ & - & $\begin{array}{l}146 \\
\text { (4 RCTs) }\end{array}$ & $\begin{array}{l}\oplus \bigcirc \bigcirc \bigcirc \\
\text { Very low }\end{array}$ & $\begin{array}{l}\text { EORTC QLQ-C30 global } \\
\text { health value (higher } \\
\text { means better) }\end{array}$ \\
\hline Quality of life ( $>5$ years) & $\begin{array}{l}\text { The mean quality of life } \\
\text { ( }>5 \text { years) was } 58\end{array}$ & $\begin{array}{l}\text { The mean quality of life } \\
\text { ( }>5 \text { years) in the inter- } \\
\text { vention group was } 8.45 \\
\text { more }(0.27 \text { fewer to } 17\end{array}$ & - & $\begin{array}{l}101 \\
\text { (2 RCTs) }\end{array}$ & $\begin{array}{l}\oplus \oplus \bigcirc \bigcirc \\
\text { Low }^{1}\end{array}$ & $\begin{array}{l}\text { EORTC QLQ-C30 global } \\
\text { health value (higher } \\
\text { means better) }\end{array}$ \\
\hline
\end{tabular}

more $(0.27$ fewer to 17

18 more) 
None of the trials reported the following outcomes: quality of life (4 weeks to 3 months), clinically significant pancreatic fistulas, serious adverse events, time to return to normal activity, time to return to work, and pain scores using a visual analogue scale

*The risk in the intervention group (and its $95 \%$ confidence interval) is based on the assumed risk in the comparison group (mean control group proportion for all outcomes except shortterm mortality where an assumed risk of $1 \%$ was used as there was no short-term mortality in the control group in the trials included in this review) and the relative effect of the intervention (and its $95 \% \mathrm{Cl}$ ).

Cl: confidence interval; HR: hazard ratio; RCT: randomised controlled trial; RR: risk ratio

\section{GRADE Working Group grades of evidence}

High quality: We are very confident that the true effect lies close to that of the estimate of the effect

Moderate quality: We are moderately confident in the effect estimate: The true effect is likely to be close to the estimate of the effect, but there is a possibility that it is substantially different Low quality: Our confidence in the effect estimate is limited: The true effect may be substantially different from the estimate of the effect

Very low quality: We have very little confidence in the effect estimate: The true effect is likely to be substantially different from the estimate of effect

${ }^{1}$ The trial(s) was/were of unclear or high risk of bias.

${ }^{2}$ Although the event was a rare event, the confidence intervals were wide even when absolute measures were used. The sample size was small.

${ }^{3}$ The $l^{2}$ value was high and there was lack of overlap of confidence intervals.

${ }^{4}$ The confidence intervals were wide and the sample size was small.

${ }^{5}$ There was inconsistency in the results. 


\section{B A C K G R O U N D}

\section{Description of the condition}

Please see the glossary of terms in Appendix 1.

The pancreas is an abdominal organ that secretes several digestive enzymes into the pancreatic ductal system, which empties into the small bowel. It also comprises the Islets of Langerhans, which secrete several hormones including insulin (NCBI 2014). Chronic pancreatitis is long-standing and progressive inflammation of the pancreas resulting in destruction and replacement of pancreatic tissue with fibrous tissue (structural deformity) (Braganza 2011). This may lead to the functional deformity of exocrine pancreatic insufficiency and endocrine pancreatic insufficiency (diabetes) ( Braganza 2011). Although previously considered as distinct from acute pancreatitis (since the pancreas returns to normal after an attack of acute pancreatitis), chronic pancreatitis is now considered to belong to the spectrum of pancreatitis disorders that include acute pancreatitis and acute recurrent pancreatitis, because of the overlapping aetiology and symptoms (Braganza 2011).

The annual incidence of chronic pancreatitis ranges from 1.5 to 7.9 per 100,000 population (Dite 2001; Dominguez-Munoz 2014; Joergensen 2010; Spanier 2013; Yadav 2011). The prevalence of chronic pancreatitis ranges from 17 to 49 per 100,000 population (Dominguez-Munoz 2014; Joergensen 2010; Yadav 2011). The annual mortality rate attributable to chronic pancreatitis is around one to four per million people (Dominguez-Munoz 2014; Spanier 2013). Alcohol is the main cause of chronic pancreatitis (Dite 2001; Joergensen 2010; Yadav 2011). Other causes include smoking; drugs such as valproate, thiazide, and oestrogens; other predisposing metabolic disorders, and diseases such as hypercalcaemia, hyperparathyroidism, and chronic renal failure; infections such as human immunodeficiency virus (HIV) and mumps; genetic mutations such as SPINK1 or CFTR mutations; obstruction of the main pancreatic duct due to cancer, scarring post ERCP (endoscopic retrograde cholangiopancreatography) or after an attack of severe pancreatitis; recurrent pancreatitis; autoimmune pancreatitis; gallstones; and idiopathic pancreatitis (including tropical pancreatitis) (Braganza 2011; Dominguez-Munoz 2014; Joergensen 2010). The reasons for these causes to result in chronic pancreatitis are poorly understood and various theories have been proposed (Braganza 2011). Increasing age and male gender are associated with a higher incidence and prevalence of chronic pancreatitis (Joergensen 2010; Spanier 2013; Yadav 2011).

While histopathological examination of a specimen of pancreas obtained by wedge biopsy or excision provides the definitive diagnosis of chronic pancreatitis, this is not practical (Braganza 2011), unless the person is undergoing surgery. Invasive methods, such as reduction of bicarbonate in duodenal aspirate after stimulation with cholecystokinin or its analogue caerulein and ductal abnormalities on ERCP, are not available routinely or cannot be recommended routinely in people with chronic abdominal pain
(Braganza 2011). Secretin-enhanced magnetic resonance cholangiopancreatography (MRCP), endoscopic ultrasound (EUS), and computed tomography (CT) scans are the other tests that may be used for the diagnosis of chronic pancreatitis. CT scan, MRCP, and EUS are the common tests used in the diagnostic algorithm of chronic pancreatitis (Braganza 2011).

Various criteria have been used for the classification of chronic pancreatitis. Some of these are Ammann's criteria (Ammann 1997), the M-ANNHEIM criteria (named after the first letters of the causes of pancreatitis) (Schneider 2007), the revised Japanese clinical diagnostic criteria (Shimosegawa 2010), the Manchester classification (Bagul 2006), and the Heidelberg criteria (Buchler 2009). The presence of so many classifications is clear evidence of the lack of consensus among experts about the classification of chronic pancreatitis. The validity of these different criteria in terms of reproducibility and implications has not been compared in order to allow the recommendation of one classification system over another. In general, the criteria for classification of chronic pancreatitis include one or more of the following features: chronic abdominal pain, exocrine pancreatic insufficiency (pancreatic enzyme deficiency that leads to indigestion of food and is manifested clinically by steatorrhoea, bloating, and excessive flatulence or established by decreased stool elastase), calcifications in the pancreas, pancreatic ductal abnormalities, and histopathological diagnosis. In addition to the symptoms mentioned above, people may also develop symptoms related to complications associated with chronic pancreatitis, such as diabetes, pancreatic pseudocysts, and biliary obstruction (Braganza 2011).

Chronic abdominal pain is the major manifestation of chronic pancreatitis. The pain is usually in the upper abdomen and is usually described as deep, penetrating, and radiating to the back (Fasanella 2007). Various theories exist as to the pathogenesis of pain in people with chronic pancreatitis. The major theories are pancreatic duct hypertension caused by calcification and fibrosis resulting from inflammation; increased pancreatic tissue pressure due to fibrosis of the peripancreatic capsule and parenchyma; neural pain; pain due to bile duct and duodenal stenosis resulting from pancreatic fibrosis; and pain resulting from pancreatic exocrine insufficiency (Di Sebastiano 2004; Fasanella 2007). There are various theories for the origin of pain in chronic pancreatitis, therefore various treatments have been proposed for its management, including surgical excision (please see Description of the intervention; How the intervention might work), surgical drainage (Puestow's procedure), pancreatic enzyme supplementation (D'Haese 2014), somatostatin analogue octreotide (Malfertheiner 1995), pregabalin (Olesen 2011), coeliac plexus blocks and neurolysis (Puli 2009), and thoracic splanchnicectomy (division of thoracic splanchnic nerves that carry the sympathetic and sensory fibres from the abdominal organs including the pancreas) (Bradley 2003). Other treatments, such as antioxidants, are aimed at preventing the oxidative damage that plays a role in the pathogenesis of chronic pancreatitis (Ahmed Ali 2014). There is 
no consensus among experts about the selection of people with chronic pancreatitis for surgical management, but pain and complications are the major indications (Shah 2009).

\section{Description of the intervention}

Surgical excision can be performed by pancreaticoduodenectomy (PD) (the standard Whipple procedure or pylorus-preserving pancreaticoduodenectomy (PPPD), where the pancreas head along with duodenum and distal end of the bile duct, which drains into the duodenum, are resected) or by duodenum-preserving pancreatic head resection (DPPHR) (Bachmann 2010; Shah 2009). PD involves excision of the head of the pancreas and duodenum. The two major types are the classical Whipple procedure and the pylorus-preserving pancreatoduodenectomy (Bachmann 2010; Shah 2009). DPPHR involves resection of the pancreatic head without excision of duodenum. This avoids the necessity for gastroenteric and biliary enteric anastomoses. The two major types are Beger procedure and Frey procedure (Bachmann 2010). Frey procedure involves a drainage procedure to anastomose the duct in the pancreatic remnant to the jejunum by a longitudinal pancreatojejunostomy in addition to pancreatic head excision, leaving behind a cuff of pancreas on the duodenal wall (Bachmann 2010). Several variations of DPPHR, such as the Hamburg procedure and the Berne procedure, have been reported (Bachmann 2010). Complications related to PD and DPPHR include pancreatic fistula, bleeding requiring blood transfusion, perforation, bile leak, or anastomotic leak requiring re-operation, and medical complications such as pneumonia (Buchler 1995; Izbicki 1995).

\section{How the intervention might work}

The main purpose of surgical excision is removal of the head of the pancreas to decompress the obstructed ducts (Braganza 2011). Since one of the theories of the pathogenesis of the pain of pancreatitis is pancreatic duct hypertension caused by obstruction of the pancreatic duct, relief of this obstruction can lead to relief of symptoms. PD is a more extensive procedure (as there is a necessity for gastroenteric and biliary enteric anastomoses) and in the past it was generally considered the standard pancreatic resection. It is performed on the assumption that a significant proportion of people with chronic pancreatitis have duodenal and bile duct stenosis (Bachmann 2010). Surgery may also be performed if it is not possible to rule out pancreatic cancer in people with symptoms suggestive of chronic pancreatitis (Bachmann 2010).

\section{Why it is important to do this review}

There is currently no consensus on the surgical management of chronic pancreatitis (Braganza 2011). This review provides the best level of evidence on the comparative benefits and harms of
DPPHR versus PD in people with chronic pancreatitis for whom pancreatic resection is considered the main treatment option, and so allow such patients and the surgeons involved in their care to make informed decisions.

\section{O B J E C T I VES}

To assess the benefits and harms of duodenum-preserving pancreatic head resection versus pancreaticoduodenectomy in people with chronic pancreatitis for whom pancreatic resection is considered the main treatment option.

\section{METHODS}

\section{Criteria for considering studies for this review}

\section{Types of studies}

We included randomised controlled trials (RCTs) only. We included studies reported in full text, and planned to include studies published as an abstract only, and unpublished data.

\section{Types of participants}

We included adults with chronic pancreatitis undergoing surgical management for chronic pancreatitis. We excluded people undergoing distal pancreatectomy or drainage procedures without any pancreatic head resection, such as Puestow's procedure.

\section{Types of interventions}

We included trials comparing DPPHRs (Beger procedure, Frey procedure, or other variations of DPPHR) and PD (PPPD or Whipple procedure). We excluded trials comparing different types of DPPHR (Beger procedure with Frey procedure) or trials comparing different types of pancreatic head resection (PPPD with Whipple procedure).

\section{Types of outcome measures}

\section{Primary outcomes}

1. All-cause mortality.

i) Short-term mortality (in-hospital mortality or mortality within three months).

ii) Long-term mortality (maximal follow-up).

2. Treatment-related serious adverse events (within three months). We accepted the following definitions of serious adverse events. 
i) Clavien-Dindo classification (Clavien 2009; Dindo 2004): Grade III or greater.

ii) International Conference on Harmonisation - Good Clinical Practice (ICH-GCP) guideline (ICH-GCP 1996): serious adverse events defined as any untoward medical occurrence that resulted in death, was life-threatening, required hospitalisation or prolongation of existing hospitalisation, or resulted in persistent or significant disability/incapacity.

iii) Individual complications such as anastomotic leak requiring re-operation that can clearly be classified as Grade III or greater with the Clavien-Dindo classification (Clavien 2009; Dindo 2004), or as a serious adverse event with the ICH-GCP classification.

iv) Clinically significant pancreatic fistulas (Type B or Type C International Study Group on Pancreatic Fistula Definition (ISGPF)) (Bassi 2005).

3. Health-related quality of life following surgery (using any validated scale such as EQ5D or 36-item Short Form (SF-36)) (EuroQol 2014; Ware 2014). EQ5D assesses the quality of life under five domains, namely mobility, self care, usual activities, pain or discomfort, and anxiety or depression (EuroQol 2014). SF-36 assesses the quality of life under eight sections, namely vitality, physical functioning, bodily pain, general health perceptions, physical role functioning, emotional role functioning, social role functioning, and mental health (Ware 2014).

i) Short-term (four weeks to three months).

ii) Medium-term (three months to five years).

iii) Long-term (more than five years).

\section{Secondary outcomes}

1. Treatment-related adverse events (within three months), such as wound infection or chest infection requiring antibiotic treatment. We accepted all adverse events reported by the study author irrespective of the severity of the adverse event.

2. Measures of earlier postoperative recovery.

i) Length of hospital stay (including the index admission (admission during which the surgery was performed) for pancreatic head resection and any surgical complication-related re-admissions).

ii) Time to return to normal activity (return to preoperative mobility without any additional carer support or as defined by authors).

iii) Time to return to work (in people who were employed previously).

3. Proportion of people in employment at maximal follow-up.

4. Pain scores using a visual analogue scale.

i) Short-term (four weeks to three months).

ii) Medium-term (three months to five years).

iii) Long-term (more than five years).

5. Measures of endocrine and exocrine insufficiency at maximal follow-up. i) Diabetes mellitus (incidence proportion).

ii) Symptoms related to exocrine insufficiency (prevalence proportion).

We based the choice of the above clinical outcomes on the necessity to assess whether DPPHR is safe and beneficial in terms of earlier postoperative recovery allowing earlier discharge from hospital, return to normal activity, and return to work, and improvement in health-related quality of life.

Reporting of the outcomes listed here will not be an inclusion criterion for the review.

\section{Search methods for identification of studies}

\section{Electronic searches}

We conducted a literature search to identify all published and unpublished RCTs. The literature search identified potential studies in all languages. We translated the non-English language papers and assess them fully for potential inclusion in the review as necessary.

We searched the following electronic databases for identifying potential studies:

1. Cochrane Central Register of Controlled Trials

(CENTRAL) (Appendix 2);

2. MEDLINE (1966 to June 2015) (Appendix 3);

3. EMBASE (1988 to June 2015) (Appendix 4); and

4. Science Citation Index (1982 to June 2015) (Appendix 5).

We also conducted a search of ClinicalTrials.gov (Appendix 6) and World Health Organization - International Clinical Trials Registry Platform (WHO ICTRP) on 22 June 2015 (Appendix 7).

\section{Searching other resources}

We checked the reference lists of all primary studies and review articles for additional references. We contacted the authors of identified trials and ask them to identify other published and unpublished studies.

We searched for errata or retractions from eligible trials on PubMed on 18 July 2015.

\section{Data collection and analysis}

\section{Selection of studies}

Three review authors (KG, CL, and $\mathrm{CH}$ ) independently screened the titles and abstracts of all the potential studies that we identified as a result of the search and coded them as 'retrieve' (eligible or potentially eligible/unclear) or 'do not retrieve'. We retrieved the full-text study reports and three review authors (KG, CL, and $\mathrm{CH}$ ) independently screened the full text, identified studies for 
inclusion, and identified and recorded reasons for exclusion of the ineligible studies. We resolved any disagreement through discussion. We identified and excluded duplicate references and collated multiple reports of the same study so that each study rather than each report was the unit of interest in the review. We recorded the selection process in sufficient detail to complete a PRISMA flow diagram and Characteristics of excluded studies table.

\section{Data extraction and management}

We used a standard data collection form for study characteristics and outcome data, which was piloted on at least one study in the review. Two review authors (KG and CL) extracted study characteristics from the included studies. We planned to extract the following study characteristics:

1. methods: study design, total duration of study and run-in, number of study centres and location, study setting,

withdrawals, date of study;

2. participants: number, mean age, age range, gender, American Society of Anesthesiologists (ASA) status (ASA 2015), inclusion criteria, exclusion criteria;

3. interventions: intervention, comparison, concomitant interventions;

4. outcomes: primary and secondary outcomes specified and collected, time points reported;

5. notes: funding for trial, notable conflicts of interest of trial authors.

Two review authors (KG and CL) independently extracted outcome data from the included studies. If outcomes were reported at multiple time points, for example, long-term health-related quality of life was reported at seven years and 15 years, we chose the later time point (i.e. 15 years) for data extraction. For time-toevent outcomes, we extracted data to calculate the natural logarithm of the hazard ratio (HR) and its standard error using the methods suggested by Parmar et al. (Parmar 1998).

We included all randomised participants for medium- and longterm outcomes (e.g. mortality or quality of life) and this was not conditional upon the short-term outcomes (e.g. being alive at three months or having a low or high quality of life index at three months), and we included all participants for medium- and longterm outcomes.

We planned to note in the Characteristics of included studies table if outcome data were reported in an unusable way. We resolve disagreements by discussions and arriving at a consensus. One review author $(\mathrm{KG})$ copied across the data from the data collection form into Review Manager 5 (RevMan 2014). We double checked that the data were entered correctly by comparing the study reports with how the data were presented in the systematic review.

\section{Assessment of risk of bias in included studies}

Two review authors (KG and CL) independently assessed the risk of bias for each study using the criteria outlined in the Cochrane
Handbook for Systematic Reviews of Interventions (Higgins 2011). We resolved any disagreements by discussion or by involving a third assessor (BRD). We assessed the risk of bias according to the following domains:

1. random sequence generation;

2. allocation concealment;

3. blinding of participants and personnel;

4. blinding of outcome assessment;

5. incomplete outcome data;

6. selective outcome reporting;

7. other bias.

We graded each potential source of bias as high, low, or unclear and provide a quote from the study report together with a justification for our judgement in the 'Risk of bias' table. We have summarised the 'Risk of bias' judgements across different studies for each of the domains listed. We acknowledge that blinding of personnel will be impossible but blinding of participants and outcome assessors was possible. We considered blinding separately for different key outcomes where necessary. For example, for unblinded outcome assessment, the risk of bias for all-cause mortality may be very different than for a participant-reported health-related quality of life scale, since lack of blinding is unlikely to result in bias in all-cause mortality, while lack of blinding is likely to introduce a significant bias in quality of life. Where information on risk of bias related to unpublished data or correspondence with a trialist, we noted this in the 'Risk of bias' table.

When considering treatment effects, we took into account the risk of bias of the studies that contributed to that outcome.

\section{Assessment of bias in conducting the systematic review}

We conducted the review according to the published protocol and reported any deviations from it in the 'Differences between protocol and review' section of the systematic review (Gurusamy 2015).

\section{Measures of treatment effect}

We planned to analyse dichotomous data (short-term mortality, proportion of participants with adverse and serious adverse events, clinically significant pancreatic fistulas, proportion of people in employment, diabetes mellitus, and symptoms related to pancreatic insufficiency) as a risk ratio (RR) with $95 \%$ confidence interval (CI). We planned to analyse continuous data as a mean difference (MD) with $95 \%$ CI when the outcome was reported or converted to the same units in all the trials (e.g. hospital stay, time to return to normal activity, time to return to work, pain scores using a visual analogue scale) or as a standardised mean difference (SMD) with 95\% CI when different scales were used for measuring the outcome (e.g. quality of life). We have ensured that higher scores for continuous outcomes have the same meaning for the 
particular outcome, explained the direction to the reader, and reported where the directions were reversed if this was necessary. We calculated the rate ratio (RAR) with $95 \%$ CI for outcomes such as adverse events and serious adverse events, where it was possible for the same person to develop more than one adverse event (or serious adverse event). If the study authors had calculated the RaR of adverse events (or serious adverse events) in the intervention versus the control group based on Poisson regression, we planned to obtain the RaR by the Poisson regression method in preference to the $\mathrm{RaR}$ calculated based on the number of adverse events (or serious adverse events) during a certain period. We planned to calculate the HR with 95\% CI for time-to-event outcomes such as time to first adverse event (or serious adverse event) and longterm survival.

We undertook meta-analyses since the treatments, participants, and the underlying clinical question were similar enough for pooling to make sense.

A common way in which trialists indicate that they have skewed data is by reporting medians and interquartile ranges. When we encountered this we noted that the data were skewed and consider the implications of this.

Where multiple trial arms were reported in a single trial, we planned to include only the relevant arms. If two comparisons (e.g. Beger procedure versus PPPD and Frey procedure versus PPPD) had to be entered into the same meta-analysis, we planned to halve the control group to avoid double counting. The alternative way of including such trials with multiple arms is to pool the results of the Beger procedure and Frey procedure and compare this with PPPD. We planned to perform a sensitivity analysis to determine if the results of the two methods of dealing with multi-arm trials led to different conclusions.

\section{Unit of analysis issues}

The unit of analysis was the individual person undergoing pancreatic head resections for chronic pancreatitis. We did not anticipate any cluster-randomised trials for this comparison but if we had identified cluster-randomised trials, we planned to obtain the effect estimate adjusted for the clustering effect. If this was not available, we planned to perform a sensitivity analysis by excluding the trial from the meta-analysis, as the variance of the effect estimate unadjusted for the cluster effect is less than the actual variance that is adjusted for the cluster effect, giving inappropriately more weight to the cluster-RCT in the meta-analysis.

\section{Dealing with missing data}

We attempted to contact the investigators or study sponsors in order to verify key study characteristics and obtain missing numerical outcome data where possible (e.g. when data were not reported completely or when a study was identified as an abstract only). If we were unable to obtain the information from the investigators or study sponsors, we imputed the mean from the median (i.e. consider the median as the mean) and the standard deviation from the standard error or P values according to the Cochrane Handbook for Systematic Reviews of Interventions (Higgins 2011), when the data did not appear to be skewed, but we assessed the impact of including such studies as indicated in a sensitivity analysis. If we were unable to calculate the standard deviation from the standard error or P values, we imputed the standard deviation as the highest standard deviation in the remaining trials included in the outcome, fully aware that this method of imputation will decrease the weight of the studies in the meta-analysis of MD and shift the effect towards no effect for the SMD.

\section{Assessment of heterogeneity}

We used the $\mathrm{I}^{2}$ statistic to measure heterogeneity among the trials in each analysis. If we had identified substantial heterogeneity, as per the Cochrane Handbook for Systematic Reviews of Interventions (greater than $50 \%$ to $60 \%$ ), we planned to explore it by pre-specified subgroup analysis. We also assessed heterogeneity by evaluating whether there was good overlap of CIs.

\section{Assessment of reporting biases}

We attempted to contact study authors and ask them to provide missing outcome data. Where this was not possible, and the missing data were thought to introduce serious bias, we explored the impact of including such studies in the overall assessment of results by a sensitivity analysis.

If we were able to pool more than 10 trials, we planned to create and examine a funnel plot to explore possible publication biases. We planned to use Egger's test to determine the statistical significance of the reporting bias (Egger 1997). We planned to consider a P value of less than 0.05 to be statistically significant reporting bias.

\section{Data synthesis}

We performed the analysis using Review Manager 5 (RevMan 2014). We used the Mantel-Haenszel method for dichotomous data, the inverse variance method for continuous data, and the generic inverse variance method for count and time-to-event data. We used both the fixed-effect model (Demets 1987) and the random-effects model (DerSimonian 1986) for the analysis. In case of discrepancy between the two models, we reported both results; otherwise, we reported only the results from the fixed-effect model.

\section{'Summary of findings' table}

We created two 'Summary of findings' table using all the outcomes. We used the five GRADE considerations (study limitations, consistency of effect, imprecision, indirectness, and publication bias) to assess the quality of the body of evidence as it relates to the studies that contribute data to the meta-analyses for the pre-specified outcomes. We have used the methods and recommendations described in Chapter 8.5 and Chapter 12 of the Cochrane Handbook 
for Systematic Reviews of Interventions (Higgins 2011), and using GRADEpro software. We justified all decisions to downgrade or upgrade the quality of studies using footnotes and we made comments to aid the reader's understanding of the review where necessary. We considered whether there was any additional outcome information that could not be incorporated into the meta-analyses, and planned to note this in the comments and state whether it supports or contradicts the information from the meta-analyses.

\section{Subgroup analysis and investigation of heterogeneity}

We planned to carry out the following subgroup analyses:

1. people at different anaesthetic risks (ASA I or II (a healthy person or mild systemic disease) versus ASA III or more (a person with severe systemic disease or worse);

2. different procedures (e.g. Beger procedure versus Frey procedure);

3. person with and without obstructive jaundice.

We planned to use all of the primary outcomes in subgroup analysis.

We planned to use the formal $\mathrm{Chi}^{2}$ test for subgroup differences to test for subgroup interactions.

\section{Sensitivity analysis}

We planned to perform the following sensitivity analyses defined a priori to assess the robustness of our conclusions:

1. excluding trials at unclear or high risk of bias (one of more of the 'Risk of bias' domains (other than blinding of the surgeon) classified as unclear or high);

2. excluding trials in which either the mean or standard deviation, or both, were imputed;

3. excluding cluster-RCTs in which the adjusted effect estimates were not reported;

4. exploring different methods of dealing with multi-arm trials (see Measures of treatment effect).

\section{Reaching conclusions}

We have based our conclusions only on the findings of the quantitative or narrative synthesis of included studies in this review. We have avoided making recommendations for practice and our implications for research and have given the reader a clear sense of where the focus of any future research in the area should be and what the remaining uncertainties are.

\section{RES U L T S}

\section{Description of studies}

\section{Results of the search}

We identified 755 references through electronic searches of CENTRAL (50 references), MEDLINE (OvidSP) (250 references), EMBASE (OvidSP) (246 references), Science Citation Index expanded (198 references), ClinicalTrials.gov (nine references), and WHO ICTRP (two references). After removing duplicate references, there were 544 references. We excluded 529 clearly irrelevant references through reading titles and abstracts. We retrieved 15 references for further assessment in detail, from the full publication. We excluded four references because of the reasons stated in the Characteristics of excluded studies table (Buchler 1996; Buchler 2008; Friess 1996; Riediger 2007). One reference is an ongoing trial with no interim report (Diener 2010). We could not obtain the full text of one reference (Morr 1991). Based on the title and the author list, it appears that this is a preliminary report of an included trial (Klempa 1995). In total, nine references describing five trials fulfilled the inclusion criteria (Characteristics of included studies) (Buchler 1995; Farkas 2006; Izbicki 1998; Keck 2012; Klempa 1995). Figure 1 shows the study flow diagram. 
Figure I. Study flow diagram.

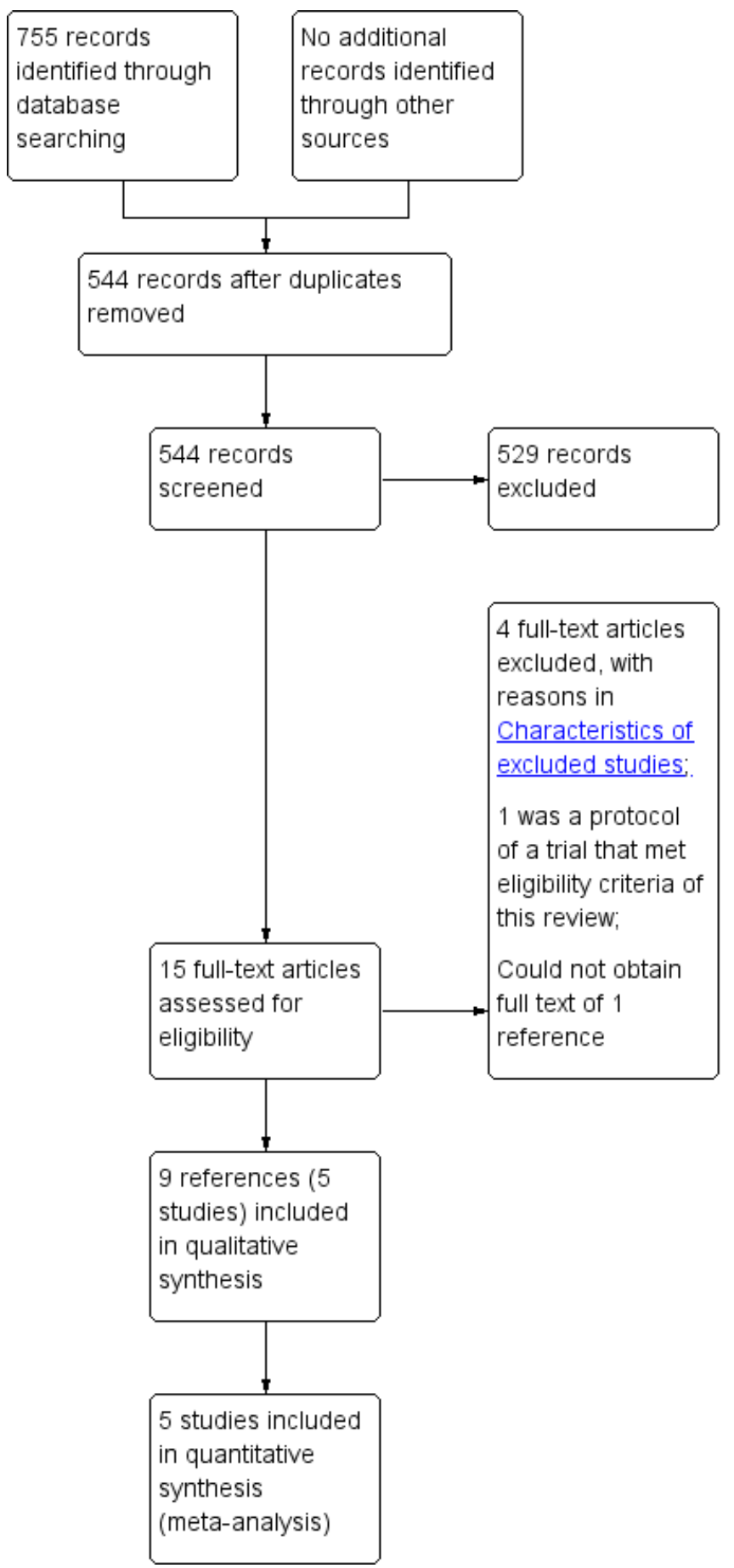




\section{Included studies}

The review included five RCTs (Buchler 1995; Farkas 2006; Izbicki 1998; Keck 2012; Klempa 1995). All the five trials were two-armed trials that included symptomatic participants with chronic pancreatitis involving the head of pancreas. The trials did not report the ASA status of the participants. All the trials were single-centre trials. All the trials included people with and without obstructive jaundice and people with and without duodenal stenosis but did not report data separately for those with and without jaundice and those with and without duodenal stenosis. The five trials randomised 292 participants (Buchler 1995; Farkas 2006; Izbicki 1998; Keck 2012; Klempa 1995). After exclusion of 23 participants in four trials (Buchler 1995; Farkas 2006; Izbicki 1998; Keck 2012) (one trial did not provide information on the number of participants randomised but simply stated the number of participants included in the trial (Klempa 1995), 269 participants were randomised to DPPHR (135 participants) and PD (134 participants). The surgical procedures compared in the five trials were:

1. Buchler 1995: Beger procedure versus Whipple procedure;

2. Farkas 2006: wide local excision of head of pancreas versus PPPD;
3. Izbicki 1998: Frey procedure versus PPPD;

4. Keck 2012: Beger or Frey procedure versus PPPD;

5. Klempa 1995: Beger procedure versus Whipple procedure.

The participants were followed up for various periods of time ranging from one to 15 years. Four studies reported mean follow-up periods, which were 14 years (Buchler 1995), one year (Farkas 2006), 15 years (Izbicki 1998), and 3.5 years (Keck 2012). One study did not report the mean follow-up period but reported the range of follow-up, which was between 3 and 5.5 years (Klempa 1995). The long-term reports were published separately from short-term reports for the two studies with long follow-up (Buchler 1995; Izbicki 1998). The Characteristics of included studies table lists the outcomes reported in individual trials.

\section{Excluded studies}

None of the excluded studies were RCTs (Buchler 1996; Buchler 2008; Friess 1996; Riediger 2007).

\section{Risk of bias in included studies}

None of the included trials were at low risk of bias. Figure 2 and Figure 3 summarises the risk of bias in the individual domains.

Figure 2. Risk of bias graph: review authors' judgements about each risk of bias item presented as percentages across all included studies.

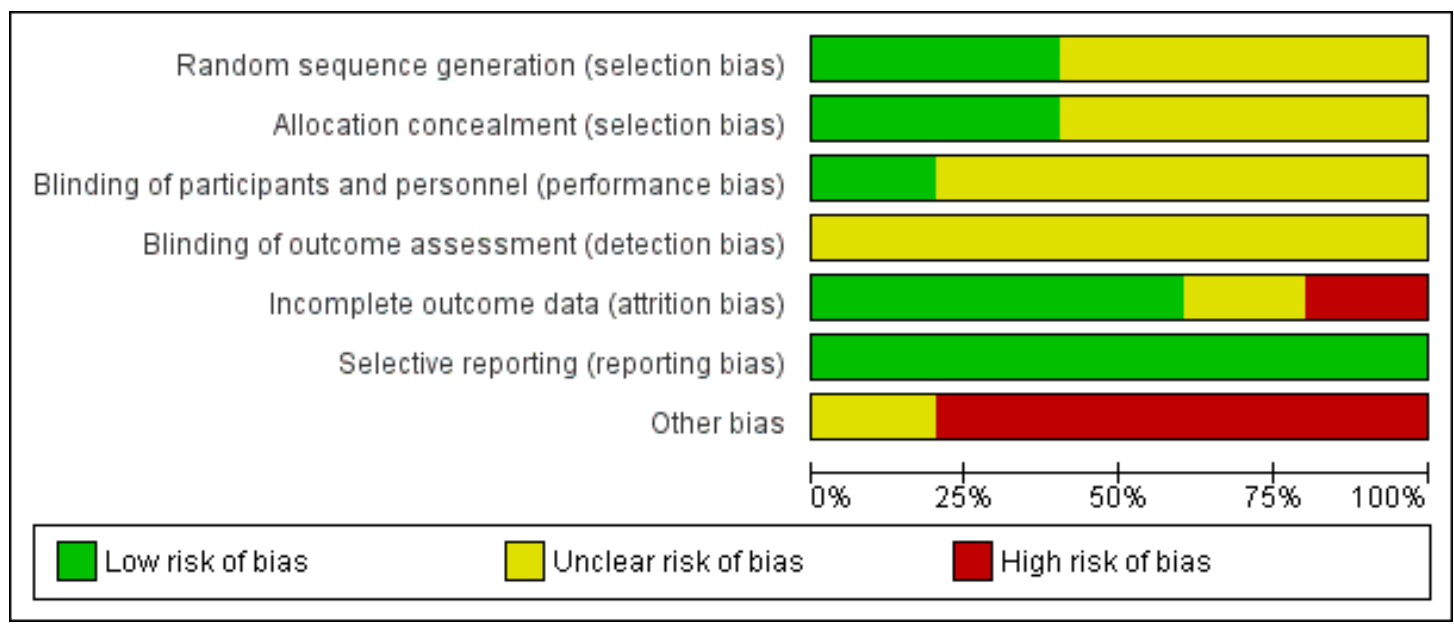

Duodenum-preserving pancreatic resection versus pancreaticoduodenectomy for chronic pancreatitis (Review) 
Figure 3. Risk of bias summary: review authors' judgements about each risk of bias item for each included study.

\begin{tabular}{|c|c|c|c|c|c|c|c|}
\hline & 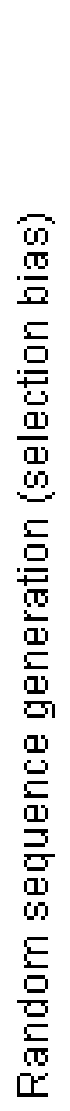 & 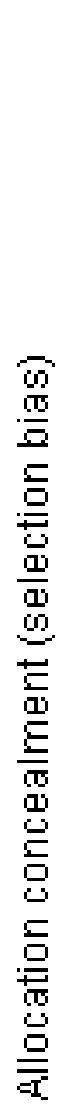 & 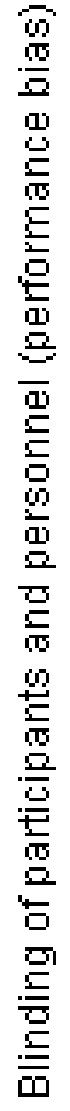 & 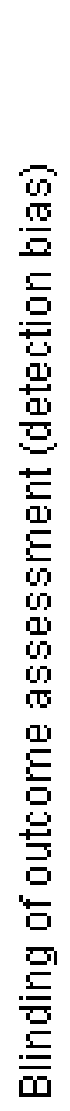 & 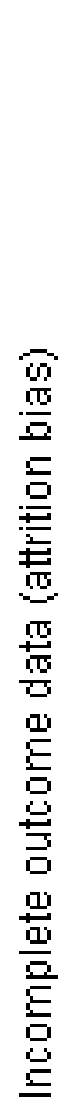 & 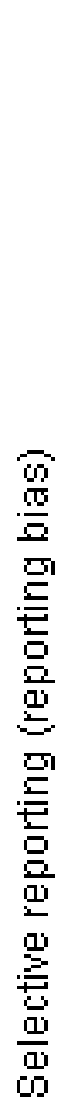 & 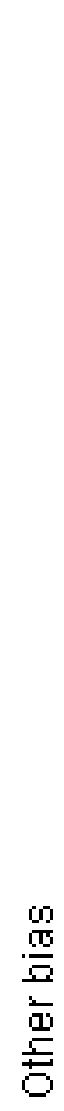 \\
\hline Buchler 1995 & $?$ & $?$ & + & $?$ & & & \\
\hline Farkas 2006 & $?$ & $?$ & $?$ & $?$ & & & \\
\hline Izbicki 1998 & & & $?$ & $?$ & & & \\
\hline Keck 2012 & $?$ & 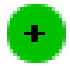 & $?$ & $?$ & & & \\
\hline Klempa 1995 & + & $?$ & $?$ & $?$ & $?$ & & ? \\
\hline
\end{tabular}




\section{Allocation}

Only one trial reported the allocation sequence generation and allocation concealment adequately and was at low risk of selection bias (Izbicki 1998). The remaining trials did not report the allocation sequence generation (Keck 2012), allocation concealment (Klempa 1995), or both (Buchler 1995; Farkas 2006), and hence are at unclear risk of selection bias.

\section{Blinding}

It is not possible to blind the surgeon performing the surgical procedure. However, it is possible to blind the participants and outcome assessors and surgeons who make clinical decisions after the surgery. None of the trials reported blinding of the participants or outcome assessors. Hence, all the trials were at unclear risk of performance bias and unclear risk of detection bias for all outcomes other than mortality. All-cause mortality was reported. Hence, it is unlikely that the lack of blinding introduced bias in assessment of mortality.

\section{Incomplete outcome data}

Four trials reported post-randomisation drop-outs due to various reasons including pancreatic cancer, failure to undergo the treatment to which they were randomised, cross-over to the other procedure because of technical requirements, participants did not require pancreatic head resection, and loss to follow-up (Buchler 1995; Farkas 2006; Izbicki 1998; Keck 2012). Of these, only one trial presented attrition bias in terms of follow-up (Keck 2012). We considered one trial that did not report the patient flow clearly at unclear risk of attrition bias (Klempa 1995).

\section{Selective reporting}

All the trials reported the clinical outcomes that are likely to be measured in such clinical trials and we considered them at low risk of selective reporting.

\section{Other potential sources of bias}

None of the trials reported the source of funding. However, it is unlikely that the source of funding would have any bias in this comparison.

Four trials reported post-randomisation drop-outs due to various reasons including pancreatic cancer, failure to undergo the treatment to which they were randomised, cross-over to the other procedure because of technical requirements, participants did not require pancreatic head resection, and loss to follow-up (Buchler 1995; Farkas 2006; Izbicki 1998; Keck 2012). All of these reasons have the potential to introduce bias in the effect estimate. For example, the tumour might have been breached in participants undergoing DPPHR and found to have pancreatic carcinoma in the frozen section or paraffin-fixed biopsy while it would not have been breached in participants undergoing PD. This might have influenced long-term survival. So these trials were at high risk of other bias. We considered one trial that did not report the patient flow clearly at unclear risk of attrition bias (Klempa 1995).

\section{Effects of interventions}

See: Summary of findings for the main comparison Duodenumpreserving pancreatic resection versus pancreaticoduodenectomy for chronic pancreatitis (primary outcomes); Summary of findings 2 Duodenum-preserving pancreatic resection versus pancreaticoduodenectomy for chronic pancreatitis (secondary outcomes)

Summary of findings for the main comparison and Summary of findings 2 summarise the effects of interventions. None of the trials reported the following outcomes: short-term quality of life (four weeks to three months), clinically significant pancreatic fistulas, serious adverse events, time to return to normal activity, time to return to work, and pain scores using a visual analogue scale.

\section{Short-term mortality (in-hospital or mortality within three months)}

All the five trials reported short-term mortality (Buchler 1995; Farkas 2006; Izbicki 1998; Keck 2012; Klempa 1995). There were two deaths in the DPPHR group (2/135 (1.5\%) participants) compared to no deaths in the PD group. There was no statistically significant difference between the two groups (RR 2.89, 95\% CI 0.31 to $26.87 ; 269$ participants; 5 studies; $\mathrm{I}^{2}=0 \%$ ) (Analysis 1.1 ). Using a random-effects model did not alter the results.

\section{Long-term mortality (maximal follow-up)}

We estimated the HRs using the methods suggested by Parmar et al. (Parmar 1998). Four trials reported long-term mortality (Buchler 1995; Izbicki 1998; Keck 2012; Klempa 1995). The follow-up period ranged between three and 15 years. Around $70 \%$ to $95 \%$ of participants were alive at five years in the various trials. Long-term mortality was statistically significantly lower in the DPPHR group than the PD group using a fixed-effect model (HR 0.71, 95\% CI 0.51 to 0.99; 229 participants; 4 studies; $\mathrm{I}^{2}=74 \%$ ). The CI of one trial (Keck 2012) did not overlap those of two other trials (Buchler 1995; Izbicki 1998) and had only a partial overlap with those of the fourth trial (Klempa 1995). This trial reported a significantly lower long-term mortality in the DPPHR group than PD group and the magnitude of the effect was greater than in the remaining trials. There was no statistically significant difference in 
the long-term mortality between the groups on using the randomeffects model (HR 0.65, 95\% CI 0.31 to $1.34 ; 229$ participants; 4 studies; $\mathrm{I}^{2}=74 \%$ ) (Analysis 1.2).

\section{Treatment-related serious adverse events}

None of the included trials reported treatment-related serious adverse events.

\section{Health-related quality of life (short term: four weeks to three months)}

None of the included trials reported short-term health-related quality of life.

\section{Health-related quality of life (medium term: three months to five years)}

Two trials reported medium-term health-related quality of life (Izbicki 1998; Keck 2012). Both trials used EORTC QLQ-C30 (EORTC 2015). Global health value was extracted since this represents the overall quality of life of the participants. This was a scale of 0 to 100 with higher values indicating a better health-related quality of life. The trials reported the median scores (Izbicki 1998; Keck 2012). One trial did not report the statistical significance of the comparison (Izbicki 1998). In the other trial, there was no statistically significant difference in medium-term healthrelated quality of life between the two groups (Pvalue $=0.66$ ). We did not perform a meta-analysis because of insufficient data but provided only a narrative summary of the results (Analysis 1.3).

\section{Health-related quality of life (long term: more than five years)}

Two trials reported long-term health-related quality of life ( Buchler 1995; Izbicki 1998). Both trials used EORTC QLQ-C30 (EORTC 2015). We extracted global health value since this represents the overall quality of life of the participants. This was a scale of 0 to 100 with higher values indicating a better healthrelated quality of life. Both the trials reported the mean and standard deviation. There was no statistically significant difference in the long-term term health-related quality of life between the two groups (MD 8.45, 95\% CI -0.27 to 17.18 ; 101 participants; 2 studies; $\mathrm{I}^{2}=0 \%$ ) (Analysis 1.4 ). Using a random-effects model did not alter the results.

\section{Treatment-related adverse events}

Four trials reported the proportion of people with adverse events in the immediate post-operative period (Buchler 1995; Farkas 2006; Izbicki 1998; Keck 2012). The proportion of participants with adverse events in the DPPHR group (23/113 (adjusted proportion $20 \%$ ) participants) was statistically significantly fewer in the PD group (41/113 (36.3\%) participants) (RR 0.57, 95\% CI 0.37 to $0.88 ; 226$ participants; 4 studies; $\mathrm{I}^{2}=64 \%$ ) when we used a fixedeffect model. This appears to be mainly due to one trial that had no adverse events in the DPPHR group (Farkas 2006). There was no statistically significant difference in the treatment-related adverse events between the groups on using a random-effects model (RR $0.55,95 \%$ CI 0.22 to $1.35 ; 226$ participants; 4 studies; $\mathrm{I}^{2}=64 \%$ ) (Analysis 1.5). One trial reported the number of adverse events. There was no statistically significant difference in the number of adverse events between the two groups (DPPHR: 12/22 participants (54.3 events per 100 participants) versus PD: 12/21 participants (57.1 events per 100 participants) (RaR 0.95, 95\% CI 0.43 to 2.12 ; 43 participants; 1 studies) (Analysis 1.6). Since this was the only study that reported the number of adverse events, issues of heterogeneity and fixed-effect versus random-effects model did not arise.

\section{Length of hospital stay}

Four trials reported the length of hospital stay (Buchler 1995; Farkas 2006; Keck 2012; Klempa 1995). Two trials reported the median length of hospital stay (Buchler 1995; Keck 2012). Of these, one trial provided the $P$ value from which we could calculate the standard deviation (Keck 2012), while the other trial did not provide any measure from which we could calculate the standard deviation (Buchler 1995). Two trials reported the mean length of hospital stay (Farkas 2006; Klempa 1995). Of these, one trial reported the standard deviation (Farkas 2006). We did not perform a meta-analysis because of insufficient information. We have tabulated the results of length of hospital stay reported in these trials in Analysis 1.7. Two trials reported statistically significant differences in the mean length of hospital stay (about five days fewer hospital stay in the DPPHR group compared to the PD group) (Farkas 2006; Klempa 1995), while the two trials that reported median length of hospital stay reported one day fewer hospital stay in the DPPHR group compared to the PD group (Buchler 1995; Keck 2012). There was no statistically significant difference in one trial (Keck 2012), while the other trial did not report the statistical significance (Buchler 1995). Thus, the hospital stay was one to five days lower in the DPPHR group compared to the PD group, although this was statistically significant in two trials only (Farkas 2006; Klempa 1995). The overall impression was that there was a decrease in the length of hospital in the DPPHR group compared to the PD group.

\section{Proportion of people in employment at maximal follow-up}

Four trials reported the proportion of people in employment (Buchler 1995; Izbicki 1998; Keck 2012; Klempa 1995). The follow-up period varied between three and 15 years. The proportion of people employed was statistically significantly higher with the 
DPPHR group (65/98 (adjusted proportion, i.e. absolute effect obtained by meta-analysis 69.4\%) participants) than the PD group (41/91 (45.1\%) participants) using a fixed-effect model (RR 1.52, $95 \%$ CI 1.18 to $1.97 ; 189$ participants; 4 studies; $\left.\mathrm{I}^{2}=43 \%\right)$. There was no statistically significant difference in the proportion of people in employment between the groups on using the random-effects model (RR 1.54, 95\% CI 1.00 to 2.37; 189 participants; 4 studies; $\mathrm{I}^{2}=43 \%$ ) (Analysis 1.8).

\section{Pain scores}

None of the included trials reported pain scores.

\section{Diabetes mellitus}

All five trials reported new-onset diabetes mellitus (Buchler 1995; Farkas 2006; Izbicki 1998; Keck 2012; Klempa 1995). The follow-up period varied between one and 15 years). There was no statistically significant difference in the proportion of people who developed diabetes mellitus between the two groups (DPPHR: 25/135 (adjusted proportion 18.6\%) participants versus PD: 32/ $134(23.9 \%)$ participants) (Analysis 1.9). Using the random-effects model did not alter the results.

\section{Measures of exocrine insufficiency}

Four trials reported long-term mortality (Buchler 1995; Izbicki 1998; Keck 2012; Klempa 1995). The follow-up period varied between three and 15 years. There was no statistically significant difference in the proportion of people who developed diabetes mellitus between the two groups (DPPHR: 62/98 (adjusted proportion 62.0\%) participants versus PD: 68/91 (74.7\%) participants) (Analysis 1.10). Using the random-effects model did not alter the results.

\section{Subgroup analysis}

None of the trials reported separate data for people with different ASA status and for people with and without jaundice. Therefore, we did not perform these subgroup analyses. With regards to the different types of interventions and control, the test for subgroup differences was not statistically significant for short-term mortality, long-term mortality, and quality of life (greater than five years) (Analysis 2.1; Analysis 2.2; Analysis 2.4). However, the treatment effects appeared to be different between the subgroups of Beger procedure versus classical Whipple and Frey procedure versus pylorus-preserving pancreatoduodenectomy, although there was only one trial comparing Frey procedure versus pylorus-preserving pancreatoduodenectomy and there was no statistically significant difference for the test for subgroup differences. We could not perform the test for subgroup differences for quality of life (three months to one year) since a narrative summary was performed for this outcome and because there was only one subgroup for this outcome.

\section{Sensitivity analysis}

All the trials were at unclear or high risk of bias. Therefore, we could not perform a sensitivity analysis of excluding trials at unclear or high risk of bias. We did not perform a sensitivity analysis excluding trials in which either mean or standard deviation was imputed since three of the four trials imputed either the mean or standard deviation in the only outcome in which the sensitivity analysis was relevant (length of hospital stay) (Buchler 1995; Keck 2012; Klempa 1995). Instead, we assessed whether the interpretation would have changed by using a narrative summary as mentioned earlier. There were no cluster RCTs; therefore, we could not perform a sensitivity analysis excluding cluster RCTs that did not report adjusted results. All the trials were two-armed trials; therefore, we could not perform a sensitivity analysis using different methods of dealing with multi-arm trials.

\section{Reporting bias}

We did not explore reporting bias using a funnel plot since there were fewer than 10 trials included in this review. 


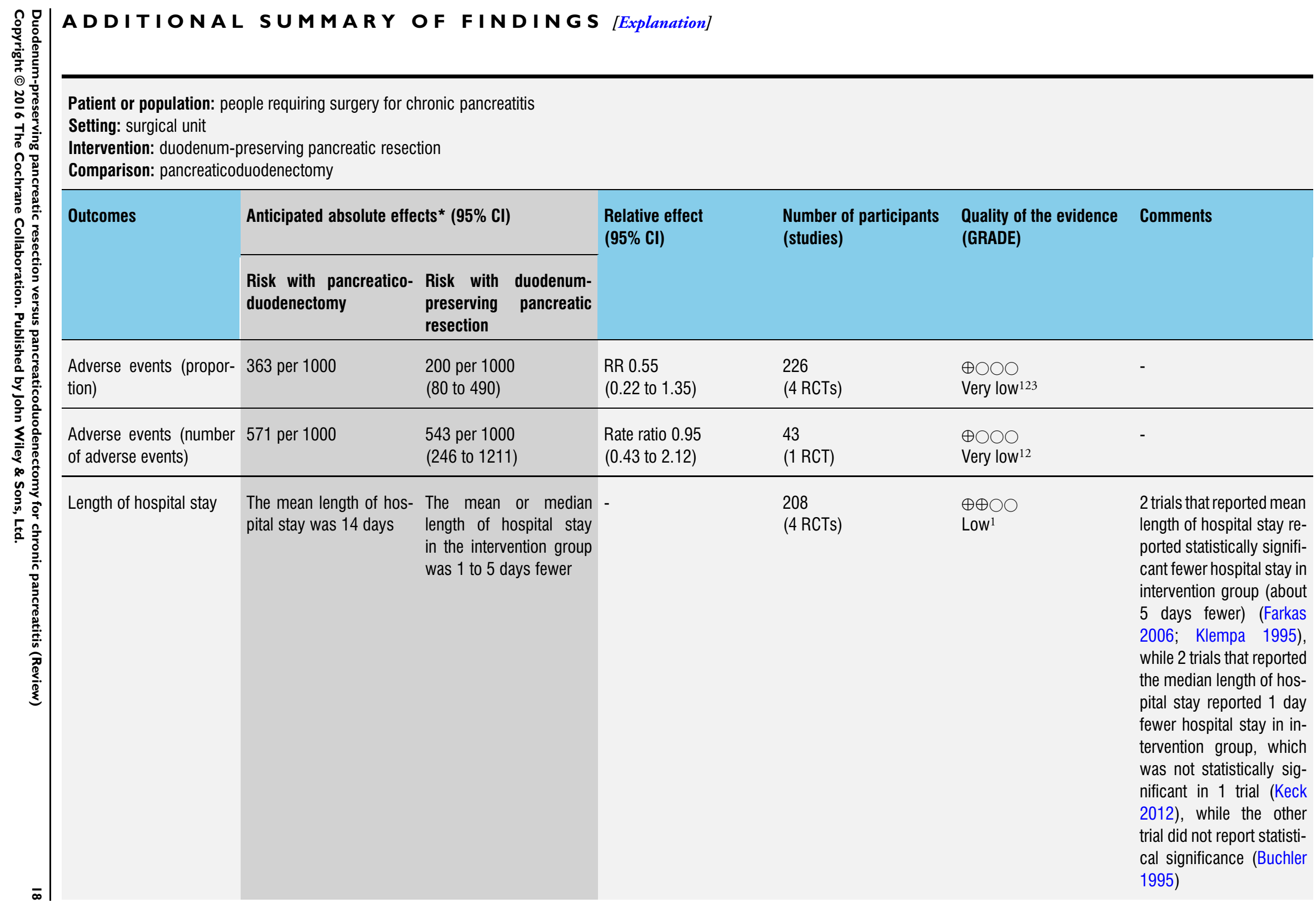




\begin{tabular}{|c|c|c|c|c|c|c|}
\hline Employed & 451 per 1000 & $\begin{array}{l}694 \text { per } 1000 \\
\text { (451 to } 1000)\end{array}$ & $\begin{array}{l}\text { RR } 1.54 \\
\text { (1.00 to } 2.37)\end{array}$ & $\begin{array}{l}189 \\
\text { (4 RCTs) }\end{array}$ & $\begin{array}{l}\oplus \oplus \bigcirc \bigcirc \\
\text { Low }^{1}\end{array}$ & - \\
\hline New-onset diabetes & 239 per 1000 & $\begin{array}{l}186 \text { per } 1000 \\
(119 \text { to } 291)\end{array}$ & $\begin{array}{l}\text { RR } 0.78 \\
\text { (0.50 to } 1.22)\end{array}$ & $\begin{array}{l}269 \\
\text { (5 RCTs) }\end{array}$ & $\begin{array}{l}\oplus \bigcirc \bigcirc \bigcirc \\
\text { Very low }\end{array}$ & - \\
\hline $\begin{array}{l}\text { Pancreatic exocrine in- } \\
\text { sufficiency }\end{array}$ & 747 per 1000 & $\begin{array}{l}620 \text { per } 1000 \\
(508 \text { to } 762)\end{array}$ & $\begin{array}{l}\text { RR } 0.83 \\
\text { (0.68 to 1.02) }\end{array}$ & $\begin{array}{l}189 \\
\text { (4 RCTs) }\end{array}$ & $\begin{array}{l}\oplus \bigcirc \bigcirc \bigcirc \\
\text { Very low } 1,2,4\end{array}$ & - \\
\hline
\end{tabular}

None of the trials reported the following outcomes: quality of life (4 weeks to 3 months), clinically significant pancreatic fistulas, serious adverse events, time to return to normal activity, time to return to work, and pain scores using a visual analogue scale

${ }^{*}$ The risk in the intervention group (and its $95 \%$ confidence interval) is based on the assumed risk in the comparison group (mean control group proportion for all outcomes except shortterm mortality where an assumed risk of $1 \%$ was used as there was no short-term mortality in the control group in the trials included in this review) and the relative effect of the intervention (and its $95 \% \mathrm{Cl}$ ).

Cl: confidence interval; RCT: randomised controlled trial; RR: risk ratio

\section{GRADE Working Group grades of evidence}

High quality: We are very confident that the true effect lies close to that of the estimate of the effect

Moderate quality: We are moderately confident in the effect estimate: The true effect is likely to be close to the estimate of the effect, but there is a possibility that it is substantially different Low quality: Our confidence in the effect estimate is limited: The true effect may be substantially different from the estimate of the effect

Very low quality: We have very little confidence in the effect estimate: The true effect is likely to be substantially different from the estimate of effect

${ }^{1}$ The trial(s) was/were of unclear or high risk of bias.

2 The confidence intervals were wide and the sample size was small.

3 The $\mathrm{I}^{2}$ value was high

${ }^{4}$ The $^{2}$ value was high and there was lack of overlap of confidence intervals. 


\section{ISCUSSION}

\section{Summary of main results}

We identified five trials of 269 participants with chronic pancreatitis requiring surgery who received DPPHR (135 participants) or PD (134 participants) (Buchler 1995; Farkas 2006; Izbicki 1998; Keck 2012; Klempa 1995). None of the trials reported short-term quality of life, clinically significant pancreatic fistulas, serious adverse events, time to return to normal activity, time to return to work, and pain scores using a visual analogue scale. There were no statistically significant differences in short-term or long-term mortality, medium-term or long-term quality of life, proportion of people with adverse events, number of people with adverse events, proportion of people employed, incidence proportion of diabetes mellitus, and prevalence proportion of pancreatic exocrine insufficiency. The length of hospital stay appeared to be lower in the DPPHR compared to PD and ranged between a reduction of one and five days in the trials. The reason for the reduction in the length of hospital day could not be explained from the information available in this review.

\section{Overall completeness and applicability of evidence}

All participants included in the trials in this review were people with symptomatic chronic pancreatitis who required surgery for their symptoms and were fit to undergo major surgery. Therefore, this review is applicable only for people with symptomatic chronic pancreatitis who are fit to undergo major surgery. All the trials included people with and without obstructive jaundice and people with and without duodenal stenosis. Therefore, this review is applicable for all people who require surgical treatment for chronic pancreatitis involving the head of the pancreas. The common DPPHR procedures such as Beger procedure and Frey procedures were compared with PPPD and Whipple procedure. Therefore, the results of this review are applicable to all these common procedures performed in the course of surgical management of people with chronic pancreatitis.

\section{Quality of the evidence}

The quality of evidence was either low or very low (Summary of findings for the main comparison). The major reason for downgrading the evidence was the risk of bias in the trials. All the trials were at unclear or high risk of bias. One of the major sources of bias was the lack of information on observer blinding for important outcomes such as assessment of adverse events, decision to discharge the participants, and assessment of quality of life. Lack of blinding might introduce detection bias and performance bias. Another major source of bias was 'other' bias. A total of 23/292
(7.9\%) participants were excluded from the analysis for various reasons. Of these, the reason for post-randomisation drop-out was due to loss to follow-up of two participants in one trial (Keck 2012). The remaining participants were excluded from analysis because they had pancreatic malignancy detected intra-operatively, underwent different procedures compared to planned procedure due to intra-operative findings, or did not undergo pancreatic head resection despite symptoms that were initially deemed to warrant surgical resection. The type of procedure performed in the excluded participants could potentially affect the outcome of these participants. If pancreatic cancer was found after the resection, it is likely that participants undergoing the PD (either PPPD or Whipple procedure) would have a more complete surgery in terms of cancer clearance than people who underwent DPPHR. Since information about pancreatic cancer is available only after the resection but the main question is whether to perform DPPHR or $\mathrm{PD}$, a decision that has to be made prior to the resection, a strict intention-to-treat analysis has to be performed in future trials. The ongoing ChroPac trial appears to overcome all these defects in the trials included in this review as the protocol includes participant and observer blinding and an intention-to-treat analysis (Diener 2010). While we have classified all the trials to be free from selective reporting bias, since the trials reported the surgeryrelated mortality and complications, it should be noted that the trials reported surgery-related complications but did not report the importance of these complications for patient recovery. While we acknowledge that this is the current standard practice in surgical trials, the severity of the complications and their impact on patient recovery should be reported in future trials.

Another major issue affecting the quality of evidence was the consistency of evidence. While there was consistency in short-term mortality, long-term quality of life, length of hospital stay (all trials indicated a reduction in hospital stay although there was inconsistency about the amount of reduction, i.e. the inconsistency noted was in the magnitude of effect rather than the direction of effect) and statistical significance, proportion of people employed at three to 15 years, and incidence of diabetes mellitus between one and 15 years, there was significant inconsistency in the remaining outcomes. Since there is no universal definition of pancreatic exocrine insufficiency (Lindkvist 2013), there is likely to be some variability in the measurement of exocrine insufficiency. However, there is no other explanation for the heterogeneity in the other outcomes other than differences in the population (there were no major differences in the type of people included in the trials) or in the intervention (there is currently no evidence of any differences in the clinical outcomes between different DPPHR procedures (Izbicki 1995), and the ChroPac trial includes different DPPHR procedures as intervention (Diener 2010), indicating the general perception that the surgeons believe that there are no major differences in the clinical outcomes between different DPPHR procedures). Thus, the heterogeneity observed in some of the outcomes is largely unexplained and decreases the confidence in the results 
of these outcomes.

The third major issue is the precision of the outcomes. While the major advantage of a meta-analysis is the improvement in precision, the trials included in this review reported on only 269 participants randomised to DPPHR and PD. Only a fraction of these participants were included in the different outcomes, particularly for long-term outcomes. Because of this, most outcomes had imprecise results (i.e. the CIs were wide). As a result, clinically significant benefits or harms cannot be ruled out. The ChroPac trial plans to include 200 participants who will be randomised on 1:1 basis to DPPHR and PD. The inclusion of this trial may improve the precision of short-term outcomes but is unlikely to improve the precision of long-term outcomes since this trial includes a followup period of 24 months only. Although there were no statistically significant differences in long-term mortality, long-term quality of life, and the proportion of people at work at maximal followup, there was a consistent trend favouring DPPHR for long-term quality of life and proportion of people at work maximal followup. Thus, long-term follow-up is necessary to determine the true clinical differences between the treatments. Clearly, long-term follow-up of participants in RCTs is difficult and can be a very high resource-consuming activity. Linking trial participants to health databases (e.g. general practitioner (GP) register), social databases (e.g. unemployment registers), and mortality registers may overcome this difficulty to a certain extent.

\section{Potential biases in the review process}

We have added two outcomes, namely long-term mortality and proportion employed at maximal follow-up. These are important clinical outcomes and addition of these clinical outcomes did not change the conclusions of this review. However, they showed that long-term follow-up is necessary to assess the true benefits and harms of the treatment.

\section{Agreements and disagreements with other studies or reviews}

There have been three previous systematic reviews of RCTs and meta-analyses on this topic (Diener 2008; Jiang 2014; Lu 2013). All these reviews concluded that DPPHR is superior to PD either in the short-term or in the long-term. We are much more cautious in our interpretation because of the quality of the evidence, in particular, the risk of bias, inconsistency in the results, and the imprecision in the results.

\section{AUTHORS, CONCLUSIONS}

\section{Implications for practice}

Low quality evidence suggested that duodenum-preserving pancreatic resection may result in shorter hospital stay than pancreaticoduodenectomy. Based on low or very low quality evidence, there is currently no evidence of any difference in the mortality, adverse events, or quality of life between duodenum-preserving pancreatic resection and pancreaticoduodenectomy. However, the results are imprecise and further randomised controlled trials are required on this topic.

\section{Implications for research}

Future randomised controlled trials comparing duodenumpreserving pancreatic resection with pancreaticoduodenectomy should report the severity of post-operative complications and their impact on a person's recovery. In such trials, participant and observer blinding should be performed and the analysis should be performed on an intention-to-treat basis to decrease bias. In addition to the short-term benefits and harms, such as mortality, surgery-related complications, quality of life, length of hospital stay, return to normal activity, and return to work, future trials should consider linkage of trial participants to health databases, social databases, and mortality registers to obtain the long-term benefits and harms the different treatments.

\section{ACKNOWLEDGEMENTS}

We thank Karin Dearness, Managing Editor, Cochrane Upper Gastrointestinal and Pancreatic Diseases (UGPD) Group, for providing administrative and logistical support for the conduct of the current review.

We thank the copy editors and Cochrane Editorial Unit for their comments. 


\section{R E F E R E N C E S}

\section{References to studies included in this review}

Buchler 1995 \{published data only\}

Buchler MW, Friess H, Muller MW, Wheatley AM, Beger HG. Randomized trial of duodenum-preserving pancreatic head resection versus pylorus-preserving Whipple in chronic pancreatitis. American Journal of Surgery 1995;169(1):65-9. Friess H, Muller MW, Buchler MW. Duodenum-preserving resection of the head of the pancreas: the future. Digestive Surgery 1994;11(3-6):318-24.

Müller MW, Friess H, Martin DJ, Hinz U, Dahmen R, Büchler MW. Long-term follow-up of a randomized clinical trial comparing Beger with pylorus-preserving Whipple procedure for chronic pancreatitis. British Journal of Surgery 2008;95(3):350-6.

Farkas 2006 \{published data only\}

Farkas G, Leindler L, Daroczi M, Farkas G Jr. Prospective randomised comparison of organ-preserving pancreatic head resection with pylorus-preserving pancreaticoduodenectomy. Langenbecks Archives of Surgery 2006;391(4):338-42.

Izbicki 1998 \{published data only\}

Bachmann K, Tomkoetter L, Kutup A, Erbes J, Vashist Y, Mann $\mathrm{O}$, et al. Is the Whipple procedure harmful for longterm outcome in treatment of chronic pancreatitis? 15 -years follow-up comparing the outcome after pylorus-preserving pancreatoduodenectomy and Frey procedure in chronic pancreatitis. Annals of Surgery 2013;258(5):815-20. Izbicki JR, Bloechle C, Broering DC, Knoefel WT, Kuechler T, Broelsch CE. Extended drainage versus resection in surgery for chronic pancreatitis: a prospective randomized trial comparing the longitudinal pancreaticojejunostomy combined with local pancreatic head excision with the pylorus-preserving pancreatoduodenectomy. Annals of Surgery 1998;228(6):771-9.

Strate T, Bachmann K, Busch P, Mann O, Schneider C, Bruhn JP, et al. Resection vs drainage in treatment of chronic pancreatitis: long-term results of a randomized trial. Gastroenterology 2008;134(5):1406-11.

Keck 2012 \{published data only\}

Keck T, Adam U, Makowiec F, Riediger H, Wellner U, Tittelbach-Helmrich D, et al. Short- and long-term results of duodenum preservation versus resection for the management of chronic pancreatitis: a prospective, randomized study. Surgery 2012;152(3 Suppl 1):S95-s102.

Klempa 1995 \{published data only\}

Klempa I, Spatny M, Menzel J, Baca I, Nustede R, Stockman F, et al. Prospective randomized study comparison of pancreatic function and quality-of-life after duodenum-preserving resection of the head of the pancreas and pancreaticoduodenectomy. Chirurg 1995;66(4):350-9.

\section{References to studies excluded from this review}

Buchler 1996 \{published data only\}

Buchler MW, Lubke D, Muller MW, Friess H. Comparison between pylorus-preserving Whipple operation and duodenum-preserving pancreatic head resection. Acta Chirurgica Austriaca 1996;28(4):200-4.

Buchler 2008 \{published data only\} Buchler MW, Warshaw AL. Resection versus drainage in treatment of chronic pancreatitis. Gastroenterology 2008; 134(5):1605-7.

Friess 1996 \{published data only\}

Friess $\mathrm{H}$. Which is the better operation in chronic pancreatitis: pylorus-preserving Whipple or duodenumpreserving pancreatic head resection?. Digestive Surgery 1996;13(2):141-9.

Riediger 2007 \{published data only\} Riediger H, Adam U, Fischer E, Keck T, Pfeffer F, Hopt UT, et al. Long-term outcome after resection for chronic pancreatitis in 224 patients. Journal of Gastrointestinal Surgery 2007;11(8):949-59.

\section{References to studies awaiting assessment}

Morr 1991 \{published data only\}

Morr H, Baca I, Schafmayer A, Klempa I. Partial duodenopancreatectomy and duodenum-preserving resection of the head of the pancreas in the treatment of chronic pancreatitis: preliminary comparative clinical trial. Langenbecks Archiv für Chirurgie 1991;Suppl:335-8.

\section{References to ongoing studies}

Diener 2010 \{published data only\} Diener MK, Bruckner T, Contin P, Halloran C, Glanemann $\mathrm{M}$, Schlitt HJ, et al. Chropac-trial: duodenum-preserving pancreatic head resection versus pancreatoduodenectomy for chronic pancreatitis. Trial protocol of a randomised controlled multicentre trial. Trials 2010;11:47.

\section{Additional references}

\section{Ahmed Ali 2014}

Ahmed Ali U, Jens S, Busch ORC, Keus F, van Goor $\mathrm{H}$, Gooszen HG, et al. Antioxidants for pain in chronic pancreatitis. Cochrane Database of Systematic Reviews 2014, Issue 8. [DOI: 10.1002/14651858.CD008945.pub2]

Ammann 1997 Ammann RW. A clinically based classification system for alcoholic chronic pancreatitis: summary of an international workshop on chronic pancreatitis. Pancreas 1997;14(3): 215-21.

ASA 2015

American Society of Anesthesiologists. ASA physical status classification system, 2015. www.asahq.org/resources/ clinical-information/asa-physical-status-classificationsystem (accessed on 6 February 2015). 
Bachmann 2010

Bachmann K, Kutup A, Mann O, Yekebas E, Izbicki JR. Surgical treatment in chronic pancreatitis timing and type of procedure. Best Practice \& Research: Clinical Gastroenterology 2010;24(3):299-310.

\section{Bagul 2006}

Bagul A, Siriwardena AK. Evaluation of the Manchester classification system for chronic pancreatitis. Journal of the Pancreas 2006;7(4):390-6.

Bassi 2005

Bassi C, Dervenis C, Butturini G, Fingerhut A, Yeo C, Izbicki J, et al. Postoperative pancreatic fistula: an international study group (ISGPF) definition. Surgery 2005;138(1):8-13.

\section{Bradley 2003}

Bradley EL 3rd, Bem J. Nerve blocks and neuroablative surgery for chronic pancreatitis. World Journal of Surgery 2003;27(11):1241-8.

Braganza 2011

Braganza JM, Lee SH, McCloy RF, McMahon MJ. Chronic pancreatitis. Lancet 2011;377(9772):1184-97.

\section{Buchler 2009}

Buchler MW, Martignoni ME, Friess H, Malfertheiner P. A proposal for a new clinical classification of chronic pancreatitis. BMC Gastroenterology 2009;9:93.

\section{Clavien 2009}

Clavien PA, Barkun J, de Oliveira ML, Vauthey JN, Dindo $\mathrm{D}$, Schulick RD, et al. The Clavien-Dindo classification of surgical complications: five-year experience. Annals of Surgery 2009;250(2):187-96.

\section{D'Haese 2014}

D'Haese JG, Ceyhan GO, Demir IE, Layer P, Uhl W, Lohr M, et al. Pancreatic enzyme replacement therapy in patients with exocrine pancreatic insufficiency due to chronic pancreatitis: a 1-year disease management study on symptom control and quality of life. Pancreas 2014;43(6): 834-41.

\section{Demets 1987}

Demets DL. Methods for combining randomized clinical trials: strengths and limitations. Statistics in Medicine 1987; 6(3):341-50.

DerSimonian 1986

DerSimonian R, Laird N. Meta-analysis in clinical trials. Controlled Clinical Trials 1986;7(3):177-88.

Di Sebastiano 2004

Di Sebastiano P, di Mola FF, Buchler MW, Friess H. Pathogenesis of pain in chronic pancreatitis. Digestive Diseases 2004;22(3):267-72.

Diener 2008

Diener MK, Rahbari NN, Fischer L, Antes G, Buchler MW, Seiler CM. Duodenum-preserving pancreatic head resection versus pancreatoduodenectomy for surgical treatment of chronic pancreatitis: a systematic review and meta-analysis. Annals of Surgery 2008;247(6):950-61.
Dindo 2004

Dindo D, Demartines N, Clavien PA. Classification of surgical complications: a new proposal with evaluation in a cohort of 6336 patients and results of a survey. Annals of Surgery 2004;240(2):205-13.

Dite 2001

Dite P, Stary K, Novotny I, Precechtelova M, Dolina J, Lata J, et al. Incidence of chronic pancreatitis in the Czech Republic. European Journal of Gastroenterology and Hepatology 2001;13(6):749-50.

Dominguez-Munoz 2014

Dominguez-Munoz JE, Lucendo A, Carballo LF, IglesiasGarcia J, Tenias JM. A Spanish multicenter study to estimate the prevalence and incidence of chronic pancreatitis and its complications. Revista Española de Enfermedades Digestivas 2014;106(4):239-45.

Egger 1997

Egger M, Davey SG, Schneider M, Minder C. Bias in metaanalysis detected by a simple, graphical test. BMJ (Clinical Research Ed.) 1997;315(7109):629-34.

\section{EORTC 2015}

EORTC Quality of Life. EORTC QLQ-C30, 2015. groups.eortc.be/qol/eortc-qlq-c30 (accessed 18 July 2015).

\section{EuroQol 2014}

EuroQol. About EQ-5D. www.euroqol.org/about-eq5d.html (accessed 8 October 2014).

\section{Fasanella 2007}

Fasanella KE, Davis B, Lyons J, Chen Z, Lee KK, Slivka A, et al. Pain in chronic pancreatitis and pancreatic cancer. Gastroenterology Clinics of North America 2007;36(2):33564, ix.

\section{Higgins 2011}

Higgins JPT, Green S (editors). Cochrane Handbook for Systematic Reviews of Interventions Version 5.1.0 [updated March 2011]. The Cochrane Collaboration, 2011. Available from www.cochrane-handbook.org.

\section{ICH-GCP 1996}

International Conference on Harmonisation of Technical Requirements for Registration of Pharmaceuticals for Human Use. Code of Federal Regulation \& ICH Guidelines. Media: Parexel Barnett, 1996.

\section{Izbicki 1995}

Izbicki JR, Bloechle C, Knoefel WT, Kuechler T, Binmoeller KF, Broelsch CE. Duodenum-preserving resection of the head of the pancreas in chronic pancreatitis. A prospective, randomized trial. Annals of Surgery 1995;221(4):350-8.

Jiang 2014

Jiang K, Wu K, Liao Y, Tu B. A meta-analysis of surgery treatment of chronic pancreatitis with an inflammatory mass in the head of pancreas: duodenum-preserving pancreatic head resection versus pancreatoduodenectomy. Chinese Journal of Surgery 2014;52(9):668-74.

\section{Joergensen 2010}

Joergensen M, Brusgaard K, Cruger DG, Gerdes AM, de Muckadell OB. Incidence, prevalence, etiology, and 
prognosis of first-time chronic pancreatitis in young patients: a nationwide cohort study. Digestive Diseases and Sciences 2010;55(10):2988-98.

Lindkvist 2013

Lindkvist B. Diagnosis and treatment of pancreatic exocrine insufficiency. World Journal of Gastroenterology 2013;19 (42):7258-66.

Lu 2013

Lu WP, Shi Q, Zhang WZ, Cai SW, Jiang K, Dong JH. A meta-analysis of the long-term effects of chronic pancreatitis surgical treatments: duodenum-preserving pancreatic head resection versus pancreatoduodenectomy. Chinese Medical Journal 2013;126(1):147-53.

Malfertheiner 1995

Malfertheiner P, Mayer D, Buchler M, Dominguez-Munoz JE, Schiefer B, Ditschuneit H. Treatment of pain in chronic pancreatitis by inhibition of pancreatic secretion with octreotide. Gut 1995;36(3):450-4.

\section{NCBI 2014}

NCBI. MeSH. NLM Controlled Vocabulary. Pancreas,

2014. www.ncbi.nlm.nih.gov/mesh/68010179 (accessed 4 July 2014).

\section{Olesen 2011}

Olesen SS, Bouwense SA, Wilder-Smith OH, van Goor $\mathrm{H}$, Drewes AM. Pregabalin reduces pain in patients with chronic pancreatitis in a randomized, controlled trial. Gastroenterology 2011;141(2):536-43.

Parmar 1998

Parmar MK, Torri V, Stewart L. Extracting summary statistics to perform meta-analyses of the published literature for survival endpoints. Statistics in Medicine 1998;17(24): 2815-34.

\section{Puli 2009}

Puli SR, Reddy JB, Bechtold ML, Antillon MR, Brugge WR. EUS-guided celiac plexus neurolysis for pain due to chronic pancreatitis or pancreatic cancer pain: a metaanalysis and systematic review. Digestive Diseases and Sciences 2009;54(11):2330-7.

RevMan 2014 [Computer program]

The Nordic Cochrane Centre, The Cochrane Collaboration. Review Manager (RevMan). Version 5.3. Copenhagen:
The Nordic Cochrane Centre, The Cochrane Collaboration, 2014.

Schneider 2007

Schneider A, Lohr JM, Singer MV. The M-ANNHEIM classification of chronic pancreatitis: introduction of a unifying classification system based on a review of previous classifications of the disease. Journal of Gastroenterology 2007;42(2):101-19.

Shah 2009

Shah NS, Siriwardena AK. Variance in elective surgery for chronic pancreatitis. Journal of the Pancreas 2009;10(1): 30-6.

Shimosegawa 2010

Shimosegawa T, Kataoka K, Kamisawa T, Miyakawa $\mathrm{H}$, Ohara $\mathrm{H}$, Ito $\mathrm{T}$, et al. The revised Japanese clinical diagnostic criteria for chronic pancreatitis. Journal of Gastroenterology 2010;45(6):584-91.

\section{Spanier 2013}

Spanier B, Bruno MJ, Dijkgraaf MG. Incidence and mortality of acute and chronic pancreatitis in the Netherlands: a nationwide record-linked cohort study for the years 1995-2005. World Journal of Gastroenterology 2013;19(20):3018-26.

Ware 2014

Ware JE. SF-36® health survey update, 2014. www.sf36.org/tools/sf36.shtml (accessed 8 October 2014).

Yadav 2011

Yadav D, Timmons L, Benson JT, Dierkhising RA, Chari ST. Incidence, prevalence, and survival of chronic pancreatitis: a population-based study. American Journal of Gastroenterology 2011;106(12):2192-9.

\section{References to other published versions of this review}

\section{Gurusamy 2015}

Gurusamy K. Duodenum-preserving pancreatic resection versus pancreaticoduodenectomy for chronic pancreatitis. Cochrane Database of Systematic Reviews 2015, Issue 2. [DOI: 10.1002/14651858.CD011521]

* Indicates the major publication for the study 


\section{CHARACTERISTICS OF STUDIES}

\section{Characteristics of included studies [ordered by study ID]}

\section{Buchler 1995}

\begin{tabular}{l|l}
\hline Methods & Randomised controlled trial \\
\hline Participants & Country: Germany \\
& Number randomised: 48 \\
& Post-randomisation drop-outs: $8(16.7 \%)$ \\
& Revised sample size: 40 \\
& Mean age (years): 45 \\
& Women: 4 (10\%) \\
& Follow-up period (years): 14 \\
& Number of study centres: 1 \\
& Inclusion criteria \\
& 1. People were enrolled in the study when they presented with pancreatic head \\
& enlargement defined as a diameter of $>4$ cm in contrast-enhanced CT scan \\
& 2. Obstruction of the common bile or pancreatic duct or duodenum \\
& 3. Entrapment of the retroperitoneal portal vein or superior mesenteric artery \\
& 4. General condition suitable for either a DPPHR or a Whipple procedure \\
\hline
\end{tabular}

Interventions

Participants were randomly assigned to 1 of 2 groups

Group 1: duodenum-preserving pancreatoduodenectomy $(\mathrm{n}=20)(23$ participants were randomised)

Further details: Beger procedure

Group 2: pancreatoduodenectomy $(\mathrm{n}=20)(25$ participants were randomised)

Further details: Whipple procedure

Outcomes

Mortality, post-operative complications, quality of life, length of hospital stay, proportion of people employed, diabetes, and exocrine insufficiency

Notes

Reasons for post-randomisation drop-outs: pancreatic cancer $(n=1)$, did not require pancreatic head resection $(\mathrm{n}=7)$

\section{Risk of bias}

\begin{tabular}{l|l|l} 
Bias & Authors' judgement & Support for judgement \\
\hline $\begin{array}{l}\text { Random sequence generation (selection } \\
\text { bias) }\end{array}$ & Unclear risk & Comment: this information was not available \\
\hline $\begin{array}{l}\text { Allocation concealment (selection bias) } \\
\text { Blinding of participants and personnel } \\
\text { (performance bias) } \\
\text { All outcomes }\end{array}$ & Low risk & Comment: this information was not available \\
\hline
\end{tabular}


Buchler 1995 (Continued)

\author{
Blinding of outcome assessment (detection Unclear risk \\ Comment: this information was not available \\ bias) \\ All outcomes
}

Incomplete outcome data (attrition bias) Low risk

All outcomes

Comment: no participants were lost to follow-up, although some participants were excluded from analysis (see other bias)

\begin{tabular}{|c|c|c|}
\hline Selective reporting (reporting bias) & Low risk & Comment: all important outcomes were reported \\
\hline Other bias & High risk & $\begin{array}{l}\text { Comment: } 1 \text { participant had pancreatic cancer intra-op- } \\
\text { eratively and underwent Whipple procedure. The group } \\
\text { to which this participant was randomised was not stated. } \\
7 \text { other participants were excluded from the analysis since } \\
\text { they did not require pancreatic head resection. All the } \\
\text { participants were symptomatic. Therefore, the reason for } \\
\text { abandoning surgeries was not clear }\end{array}$ \\
\hline
\end{tabular}

Farkas 2006

\begin{tabular}{|c|c|}
\hline Methods & Randomised controlled trial \\
\hline Participants & $\begin{array}{l}\text { Country: Hungary } \\
\text { Number randomised: } 45 \text {. } \\
\text { Post-randomisation drop-outs: } 5(11.1 \%) \\
\text { Revised sample size: } 40 \\
\text { Mean age (years): } 44 \\
\text { Women: } 10 \text { ( } 25 \% \text { ) } \\
\text { Follow-up period (years): } 1 \\
\text { Number of study centres: } 1 \\
\text { Inclusion criteria } \\
\text { 1. Pancreatic head enlargement, defined as a diameter of }>4 \mathrm{~cm} \text { in a contrast- } \\
\text { enhanced CT scan } \\
\text { 2. Intractable pain and obstruction of the common bile or pancreatic duct or } \\
\text { duodenum } \\
\text { Exclusion criteria } \\
\text { 1. Myocardial infarction within the previous } 6 \text { months } \\
\text { 2. Detection of a malignant pancreatic tumour }\end{array}$ \\
\hline Interventions & $\begin{array}{l}\text { Participants were randomly assigned to } 1 \text { of } 2 \text { groups } \\
\text { Group 1: duodenum-preserving pancreatoduodenectomy }(\mathrm{n}=20)(23 \text { participants were } \\
\text { randomised) } \\
\text { Further details: wide local excision of head of pancreas } \\
\text { Group 2: pancreatoduodenectomy }(\mathrm{n}=20)(22 \text { participants were randomised }) \\
\text { Further details: PPPD }\end{array}$ \\
\hline
\end{tabular}

Outcomes

Mortality, post-operative complications, length of hospital stay, and diabetes

Duodenum-preserving pancreatic resection versus pancreaticoduodenectomy for chronic pancreatitis (Review) 
Farkas 2006 (Continued)

$\begin{array}{ll}\text { Notes } & \text { Reasons for post-randomisation drop-outs: pancreatic carcinoma confirmed by histolog- } \\ \text { ical examination of a frozen section intraoperatively }\end{array}$

ical examination of a frozen section intraoperatively

\section{Risk of bias}

\begin{tabular}{|c|c|c|}
\hline Bias & Authors' judgement & Support for judgement \\
\hline $\begin{array}{l}\text { Random sequence generation (selection } \\
\text { bias) }\end{array}$ & Unclear risk & Comment: this information was not available \\
\hline Allocation concealment (selection bias) & Unclear risk & Comment: this information was not available \\
\hline $\begin{array}{l}\text { Blinding of participants and personnel } \\
\text { (performance bias) } \\
\text { All outcomes }\end{array}$ & Unclear risk & $\begin{array}{l}\text { Comment: information on participant blinding was not } \\
\text { available. It is impossible to blind surgeons who perform } \\
\text { the procedure }\end{array}$ \\
\hline $\begin{array}{l}\text { Blinding of outcome assessment (detection } \\
\text { bias) } \\
\text { All outcomes }\end{array}$ & Unclear risk & Comment: this information was not available \\
\hline $\begin{array}{l}\text { Incomplete outcome data (attrition bias) } \\
\text { All outcomes }\end{array}$ & Low risk & $\begin{array}{l}\text { Comment: no participants were lost to follow-up, al- } \\
\text { though some participants were excluded from analysis } \\
\text { (see other bias) }\end{array}$ \\
\hline Selective reporting (reporting bias) & Low risk & Comment: all important outcomes were reported \\
\hline Other bias & High risk & $\begin{array}{l}\text { Comment: participants were excluded because they were } \\
\text { found to have pancreatic cancer intraoperatively. This can } \\
\text { introduce bias since the intervention (duodenum-pre- } \\
\text { serving pancreatoduodenectomy) is a less invasive proce- } \\
\text { dure than control (pancreatoduodenectomy) }\end{array}$ \\
\hline
\end{tabular}

Izbicki 1998

\begin{tabular}{ll}
\hline Methods & Randomised controlled trial \\
\hline Participants & Country: Germany \\
& Number randomised: 64 \\
& Post-randomisation drop-outs: $3(4.7 \%)$ \\
& Revised sample size: 61 \\
& Mean age (years): 44 \\
& Women: 10 (16.4\%) \\
& Follow-up period (years): 15 \\
& Number of study centres: 1 \\
& Inclusion criteria \\
& 1. Inclusion criteria were an inflammatory mass in the head of the pancreas $(>35$ \\
& mm in diameter) \\
& 2. Severe recurrent pain attacks (at least 1 per month requiring opiates)
\end{tabular}

Duodenum-preserving pancreatic resection versus pancreaticoduodenectomy for chronic pancreatitis (Review) 
Izbicki 1998 (Continued)

3. History of pain attacks for at least 1 year

4. Co-existing complications from adjacent organs (e.g. common bile duct stenosis, duodenal stenosis)

\section{Exclusion criteria}

1. Chronic pancreatitis without involvement of the pancreatic head

2. Small duct disease (maximal diameter of duct Wirsung $=3 \mathrm{~mm}$ )

3. Pseudocysts without duct pathology

4. Portal vein thrombosis

5. Myocardial infarction within 6 months

6. Detection of a malignant pancreatic tumour

7. Co-existing malignancy of other organs

$\begin{array}{ll}\text { Interventions } & \text { Participants were randomly assigned to } 1 \text { of } 2 \text { groups } \\ \text { Group 1: duodenum-preserving pancreatoduodenectomy }(\mathrm{n}=31)(32 \text { participants were } \\ \text { randomised) } \\ \text { Further details: Frey procedure } \\ \text { Group 2: pancreatoduodenectomy }(\mathrm{n}=30)(32 \text { participants were randomised }) \\ \text { Further details: PPPD }\end{array}$

Outcomes

Mortality, post-operative complications, quality of life, proportion of people employed, diabetes, and exocrine insufficiency

Notes

Reasons for post-randomisation drop-outs: pancreatic carcinoma found on frozen section biopsy

\section{Risk of bias}

\begin{tabular}{lll} 
Bias & Authors' judgement & Support for judgement \\
\hline $\begin{array}{l}\text { Random sequence generation (selection } \\
\text { bias) }\end{array}$ & Low risk & $\begin{array}{l}\text { Quote: "Randomization was performed using a list of } \\
\text { random digits that were made available during surgery as } \\
\text { coded cards sealed in envelopes" }\end{array}$ \\
\hline Allocation concealment (selection bias) & Low risk & $\begin{array}{l}\text { Quote: "Randomization was performed using a list of } \\
\text { random digits that were made available during surgery as } \\
\text { coded cards sealed in envelopes" }\end{array}$
\end{tabular}

Blinding of participants and personnel Unclear risk (performance bias)

All outcomes

Blinding of outcome assessment (detection Unclear risk bias)

All outcomes

Incomplete outcome data (attrition bias) Low risk All outcomes
Comment: information on participant blinding was not available. It is impossible to blind surgeons who perform the procedure

Comment: quality of life and pain score data were recorded by doctoral students who were unaware of group allocation. It was not clear whether the remaining outcomes were assessed by blinded outcome assessors

Comment: no participants were lost to follow-up, although some participants were excluded from analysis (please see other bias) 
Izbicki 1998 (Continued)

\begin{tabular}{|c|c|c|}
\hline Selective reporting (reporting bias) & Low risk & Comment: all important outcomes were reported \\
\hline Other bias & High risk & $\begin{array}{l}\text { Comment: participants were excluded because they were } \\
\text { found to have pancreatic cancer intraoperatively. This can } \\
\text { introduce bias since the intervention (duodenum-pre- } \\
\text { serving pancreatoduodenectomy) is a less invasive proce- } \\
\text { dure than control (pancreatoduodenectomy) }\end{array}$ \\
\hline
\end{tabular}

Keck 2012

\begin{tabular}{|c|c|}
\hline Methods & Randomised controlled trial \\
\hline Participants & $\begin{array}{l}\text { Country: Germany } \\
\text { Number randomised: } 92 \\
\text { Post-randomisation drop-outs: } 7(7.6 \%) \\
\text { Revised sample size: } 85 \\
\text { Mean age (years): } 42 \\
\text { Women: } 13 \text { (15.3\%) } \\
\text { Follow-up period (years): } 3.5 \\
\text { Number of study centres: } 1 \\
\text { Inclusion criteria } \\
\text { 1. Radiological signs of chronic pancreatitis (inflammatory head mass, calcifications, } \\
\text { duct abnormalities) } \\
\text { 2. Severe recurrent pain attacks } \\
\text { 3. Complications involving adjacent organs (e.g. biliary duodenal stenosis or } \\
\text { pseudocysts) } \\
\text { Exclusion criteria } \\
\text { 1. Presence of complications not allowing PPPD and DPPHR. e.g. stenosis of distal } \\
\text { stomach, suspicion of or generalised portal hypertension }\end{array}$ \\
\hline Interventions & $\begin{array}{l}\text { Participants were randomly assigned to } 1 \text { of } 2 \text { groups } \\
\text { Group 1: duodenum-preserving pancreatoduodenectomy }(\mathrm{n}=42) \\
\text { Further details: Beger or Frey procedure } \\
\text { Group 2: pancreatoduodenectomy }(\mathrm{n}=43) \\
\text { Further details: PPPD }\end{array}$ \\
\hline Outcomes & $\begin{array}{l}\text { Mortality, post-operative complications, quality of life, length of hospital stay, proportion } \\
\text { of people employed, diabetes, and exocrine insufficiency }\end{array}$ \\
\hline Notes & $\begin{array}{l}\text { Reasons for post-randomisation drop-outs: } 2 \text { participants in PPPD group underwent } \\
\text { classic Whipple procedure and } 3 \text { participants in the DPPHR group underwent PPPD; } \\
2 \text { participants were lost to follow-up }\end{array}$ \\
\hline
\end{tabular}

Bias

Authors' judgement

Support for judgement

Duodenum-preserving pancreatic resection versus pancreaticoduodenectomy for chronic pancreatitis (Review)

Copyright $@ 2016$ The Cochrane Collaboration. Published by John Wiley \& Sons, Ltd. 
Keck 2012 (Continued)

\begin{tabular}{l|l|l}
$\begin{array}{l}\text { Random sequence generation (selection } \\
\text { bias) }\end{array}$ & Unclear risk & Comment: this information was not available \\
\hline $\begin{array}{l}\text { Allocation concealment (selection bias) } \\
\text { Blinding of participants and personnel } \\
\text { (performance bias) }\end{array}$ & Low risk & $\begin{array}{l}\text { Quote: "Randomization was performed before the oper- } \\
\text { ation via coded cards in sealed envelopes" }\end{array}$ \\
\hline
\end{tabular}

Blinding of outcome assessment (detection Unclear risk

Comment: this information was not available

bias)

All outcomes

Incomplete outcome data (attrition bias) High risk Comment: 2 participants were lost to follow-up All outcomes

\begin{tabular}{|c|c|c|}
\hline Selective reporting (reporting bias) & Low risk & Comment: all important outcomes were reported \\
\hline Other bias & High risk & $\begin{array}{l}\text { Comment: participants were excluded because they did } \\
\text { not receive the planned operation. The reasons for this } \\
\text { were: } 2 \text { participants in the PPPD group under classic } \\
\text { Whipple procedure owing to severe inflammatory in- } \\
\text { volvement of the distal stomach and } 3 \text { participants in the } \\
\text { DPPHR group underwent PPPD because of suspicion } \\
\text { of malignancy }\end{array}$ \\
\hline
\end{tabular}

\section{Klempa 1995}

\begin{tabular}{ll}
\hline Methods & Randomised controlled trial \\
\hline Participants & Country: Germany \\
& Number randomised: 43 \\
& Post-randomisation drop-outs: not stated \\
& Revised sample size: 43 \\
& Mean age (years): 47 years \\
& Women: 10 (23.3\%) \\
& Follow-up period (years): range 3-5.5 years (mean not reported) \\
& Number of study centres: 1 \\
& Inclusion criteria \\
& 1. Ongoing chronic obstructive pancreatitis for multiple (3-12) years with pain \\
& requiring analgesia or with severe pain as judged by independent investigators in a \\
& repeated manner (second opinion) \\
& 2. Complications such as choledochostenosis causing jaundice, duodenal stenosis \\
& with stomach emptying disorders, compression of the duct of Wirsung in the head part \\
of the organ, multiple pseudoaneurysm of the pancreatic head, transverse colon & stenosis, segmental portal hypertension with compression of the superior mesenteric \\
vein
\end{tabular}

Duodenum-preserving pancreatic resection versus pancreaticoduodenectomy for chronic pancreatitis (Review) 


\section{Klempa 1995 (Continued)}

\begin{tabular}{|c|c|c|}
\hline Interventions & \multicolumn{2}{|c|}{$\begin{array}{l}\text { Participants were randomly assigned to } 1 \text { of } 2 \text { groups } \\
\text { Group 1: duodenum-preserving pancreatoduodenectomy }(\mathrm{n}=22) \\
\text { Further details: Beger procedure } \\
\text { Group 2: pancreatoduodenectomy }(\mathrm{n}=21) \\
\text { Further details: Whipple procedure }\end{array}$} \\
\hline Outcomes & \multicolumn{2}{|c|}{$\begin{array}{l}\text { Mortality, post-operative complications, length of hospital stay, proportion of people } \\
\text { employed, diabetes, and exocrine insufficiency }\end{array}$} \\
\hline \multicolumn{3}{|l|}{ Notes } \\
\hline \multicolumn{3}{|l|}{ Risk of bias } \\
\hline Bias & Authors' judgement & Support for judgement \\
\hline $\begin{array}{l}\text { Random sequence generation (selection } \\
\text { bias) }\end{array}$ & Low risk & $\begin{array}{l}\text { Quote: "the patients according to the random number } \\
\text { list (created prior to the study) were classified into two } \\
\text { groups" }\end{array}$ \\
\hline Allocation concealment (selection bias) & Unclear risk & Comment: this information was not available \\
\hline $\begin{array}{l}\text { Blinding of participants and personnel } \\
\text { (performance bias) } \\
\text { All outcomes }\end{array}$ & Unclear risk & $\begin{array}{l}\text { Comment: information on participant blinding was not } \\
\text { available. It is impossible to blind surgeons who perform } \\
\text { the procedure }\end{array}$ \\
\hline $\begin{array}{l}\text { Blinding of outcome assessment (detection } \\
\text { bias) } \\
\text { All outcomes }\end{array}$ & Unclear risk & Comment: this information was not available \\
\hline $\begin{array}{l}\text { Incomplete outcome data (attrition bias) } \\
\text { All outcomes }\end{array}$ & Unclear risk & Comment: this information was not available \\
\hline Selective reporting (reporting bias) & Low risk & Comment: all important outcomes were reported \\
\hline Other bias & Unclear risk & $\begin{array}{l}\text { Comment: it was not clear whether participants were } \\
\text { excluded because of malignancy }\end{array}$ \\
\hline
\end{tabular}

CT: computed tomography; DPPHR: duodenum-preserving pancreatic head resection; n: number of participants; PPPD: pyloruspreserving pancreaticoduodenectomy. 
Characteristics of excluded studies [ordered by study ID]

\begin{tabular}{ll}
\hline Study & Reason for exclusion \\
\hline Buchler 1996 & Not a randomised controlled trial \\
\hline Buchler 2008 & Editorial on a long-term follow-up report of an included study (Izbicki 1995) \\
\hline Friess 1996 & Not a randomised controlled trial \\
\hline Riediger 2007 & Not a randomised controlled trial \\
\hline
\end{tabular}

Characteristics of studies awaiting assessment [ordered by study ID]

\section{Morr 1991}

Methods Could not obtain neither an abstract nor a full-text publication

\begin{tabular}{ll}
\hline Participants & Chronic pancreatitis \\
\hline Interventions & $\begin{array}{l}\text { Duodenum-preserving pancreatic resection (further details not available) vs. pancreaticoduodenectomy (further de- } \\
\text { tails not available) }\end{array}$ \\
\hline Outcomes & This information was not available \\
\hline Notes & $\begin{array}{l}\text { This is likely to be a preliminary report of Klempa } 1995 \text { or based on the title that states 'preliminary clinical trial' } \\
\text { and the author list }\end{array}$ \\
\hline
\end{tabular}

Characteristics of ongoing studies [ordered by study ID]

Diener 2010

\begin{tabular}{ll}
\hline Trial name or title & ChroPac \\
\hline Methods & Multicentre randomised controlled trial (observer and participant blinded) \\
\hline Participants & People scheduled for primary elective surgery for chronic head pancreatitis \\
\hline Interventions & Duodenum-preserving pancreatic resection (Beger procedure, Frey procedure, or Berne procedure) \\
\hline Outcomes & $\begin{array}{l}\text { Mortality, complications including pancreatic fistula, health-related quality of life, length of hospital stay, } \\
\text { exocrine insufficiency, and new-onset diabetes mellitus }\end{array}$ \\
\hline Starting date & 18 May 2009
\end{tabular}

Duodenum-preserving pancreatic resection versus pancreaticoduodenectomy for chronic pancreatitis (Review) 
Diener 2010 (Continued)

Contact information Dr Christoph Seiler (Christoph.Seiler@med.uni-heidelberg.de) and Prof Marcus Buchler ( Markus.Buechler@med.uni-heidelberg.de)

Notes 
DATA AND ANALYSES

Comparison 1. Duodenum-preserving pancreatic resection versus pancreaticoduodenectomy

\begin{tabular}{|c|c|c|c|c|}
\hline Outcome or subgroup title & $\begin{array}{l}\text { No. of } \\
\text { studies }\end{array}$ & $\begin{array}{c}\text { No. of } \\
\text { participants }\end{array}$ & Statistical method & Effect size \\
\hline 1 Short-term mortality & 5 & 269 & Risk Ratio (M-H, Fixed, 95\% CI) & $2.89[0.31,26.87]$ \\
\hline 2 Long-term mortality & 4 & 229 & Hazard Ratio (Random, 95\% CI) & $0.65[0.31,1.34]$ \\
\hline $\begin{array}{l}3 \text { Quality of life ( } 3 \text { months to } 5 \\
\text { years) }\end{array}$ & & & Other data & No numeric data \\
\hline 4 Quality of life (> 5 years) & 2 & 101 & Mean Difference (IV, Fixed, 95\% CI) & $8.45[-0.27,17.18]$ \\
\hline 5 Adverse events (proportion) & 4 & 226 & Risk Ratio (M-H, Random, 95\% CI) & $0.55[0.22,1.35]$ \\
\hline $\begin{array}{l}6 \text { Adverse events (number of } \\
\text { adverse events) }\end{array}$ & 1 & & Rate Ratio (Fixed, 95\% CI) & Totals not selected \\
\hline 7 Length of hospital stay & & & Other data & No numeric data \\
\hline 8 Employed & 4 & 189 & Risk Ratio (M-H, Random, 95\% CI) & $1.54[1.00,2.37]$ \\
\hline 9 New-onset diabetes & 5 & 269 & Risk Ratio (M-H, Fixed, 95\% CI) & $0.78[0.50,1.22]$ \\
\hline $\begin{array}{l}10 \text { Pancreatic exocrine } \\
\text { insufficiency }\end{array}$ & 4 & 189 & Risk Ratio (M-H, Fixed, 95\% CI) & $0.83[0.68,1.02]$ \\
\hline
\end{tabular}

Comparison 2. Duodenum-preserving pancreatic resection versus pancreaticoduodenectomy (subgroup analysis)

\begin{tabular}{|c|c|c|c|c|}
\hline Outcome or subgroup title & $\begin{array}{l}\text { No. of } \\
\text { studies }\end{array}$ & $\begin{array}{c}\text { No. of } \\
\text { participants }\end{array}$ & Statistical method & Effect size \\
\hline 1 Short-term mortality & 4 & 184 & Risk Ratio (M-H, Fixed, 95\% CI) & $2.89[0.31,26.87]$ \\
\hline $\begin{array}{l}1.1 \text { Beger procedure vs. } \\
\text { Whipple procedure }\end{array}$ & 2 & 83 & Risk Ratio (M-H, Fixed, 95\% CI) & $2.87[0.12,66.75]$ \\
\hline $\begin{array}{l}\text { 1.2 Frey procedure } \\
\text { vs. pylorus-preserving } \\
\text { pancreaticoduodenectomy }\end{array}$ & 1 & 61 & Risk Ratio (M-H, Fixed, 95\% CI) & $2.91[0.12,68.66]$ \\
\hline $\begin{array}{l}1.3 \text { Wide local excision } \\
\text { of head of pancreas } \\
\text { vs. pylorus-preserving } \\
\text { pancreaticoduodenectomy }\end{array}$ & 1 & 40 & Risk Ratio (M-H, Fixed, 95\% CI) & $0.0[0.0,0.0]$ \\
\hline 2 Long-term mortality & 3 & & Hazard Ratio (Random, 95\% CI) & $0.87[0.60,1.26]$ \\
\hline $\begin{array}{l}2.1 \text { Beger procedure vs. } \\
\text { Whipple procedure }\end{array}$ & 2 & & Hazard Ratio (Random, 95\% CI) & $1.19[0.68,2.07]$ \\
\hline $\begin{array}{l}2.2 \text { Frey procedure } \\
\text { vs. pylorus-preserving } \\
\text { pancreaticoduodenectomy }\end{array}$ & 1 & & Hazard Ratio (Random, 95\% CI) & $0.71[0.45,1.11]$ \\
\hline $\begin{array}{l}3 \text { Quality of life (3 months to } 1 \\
\text { year) }\end{array}$ & & & Other data & No numeric data \\
\hline $\begin{array}{l}\text { 3.1 Frey procedure } \\
\text { vs. pylorus-preserving } \\
\text { pancreaticoduodenectomy }\end{array}$ & & & Other data & No numeric data \\
\hline
\end{tabular}

Duodenum-preserving pancreatic resection versus pancreaticoduodenectomy for chronic pancreatitis (Review)

Copyright @ 2016 The Cochrane Collaboration. Published by John Wiley \& Sons, Ltd. 
4 Quality of life (> 5 years)

4.1 Beger procedure vs.

Whipple procedure

4.2 Frey procedure

vs. pylorus-preserving

pancreaticoduodenectomy
$101 \quad$ Mean Difference (IV, Fixed, 95\% CI)

$8.45[-0.27,17.18]$

Mean Difference (IV, Fixed, 95\% CI)

$6.70[-11.19,24.59]$

$9.0[-0.99,18.99]$

\section{Analysis I.I. Comparison I Duodenum-preserving pancreatic resection versus pancreaticoduodenectomy, Outcome I Short-term mortality.}

Review: Duodenum-preserving pancreatic resection versus pancreaticoduodenectomy for chronic pancreatitis

Comparison: I Duodenum-preserving pancreatic resection versus pancreaticoduodenectomy

Outcome: I Short-term mortality

\begin{tabular}{|c|c|c|c|c|c|}
\hline \multirow[t]{2}{*}{ Study or subgroup } & $\begin{array}{l}\text { Duodenum } \\
\text { preserving }\end{array}$ & \multirow{2}{*}{$\begin{array}{l}\text { Pancreaticoduodenectomy } \\
\qquad \mathrm{n} / \mathrm{N}\end{array}$} & Risk Ratio & \multirow[t]{2}{*}{ Weight } & \multirow{2}{*}{$\begin{array}{r}\text { Risk Ratio } \\
\mathrm{M}-\mathrm{H}, \text { Fixed,95\% Cl }\end{array}$} \\
\hline & $\mathrm{n} / \mathrm{N}$ & & M-H,Fixed,95\% Cl & & \\
\hline Buchler 1995 & $0 / 20$ & $0 / 20$ & & & Not estimable \\
\hline Farkas 2006 & $0 / 20$ & $0 / 20$ & & & Not estimable \\
\hline Izbicki 1998 & $|/ 3|$ & $0 / 30$ & & $49.8 \%$ & $2.91[0.12,68.66]$ \\
\hline Keck 2012 & $0 / 42$ & $0 / 43$ & & & Not estimable \\
\hline Klempa 1995 & $1 / 22$ & $0 / 21$ & & $50.2 \%$ & $2.87[0.12,66.75]$ \\
\hline Total $(95 \% \mathrm{CI})$ & 135 & 134 & & $100.0 \%$ & $2.89[0.31,26.87]$ \\
\hline \multicolumn{6}{|c|}{ Total events: 2 (Duodenum preserving), 0 (Pancreaticoduodenectomy) } \\
\hline \multicolumn{6}{|c|}{ Heterogeneity: Chi $^{2}=0.00, d f=I(P=1.00) ; 1^{2}=0.0 \%$} \\
\hline \multicolumn{6}{|c|}{ Test for overall effect: $Z=0.93(P=0.35)$} \\
\hline \multicolumn{6}{|c|}{ Test for subgroup differences: Not applicable } \\
\hline & & 0.01 & 0.1 & 100 & \\
\hline & & Favours duo pr & serving & inc duodenectomy & \\
\hline
\end{tabular}




\section{Analysis I.2. Comparison I Duodenum-preserving pancreatic resection versus pancreaticoduodenectomy,}

Outcome 2 Long-term mortality.

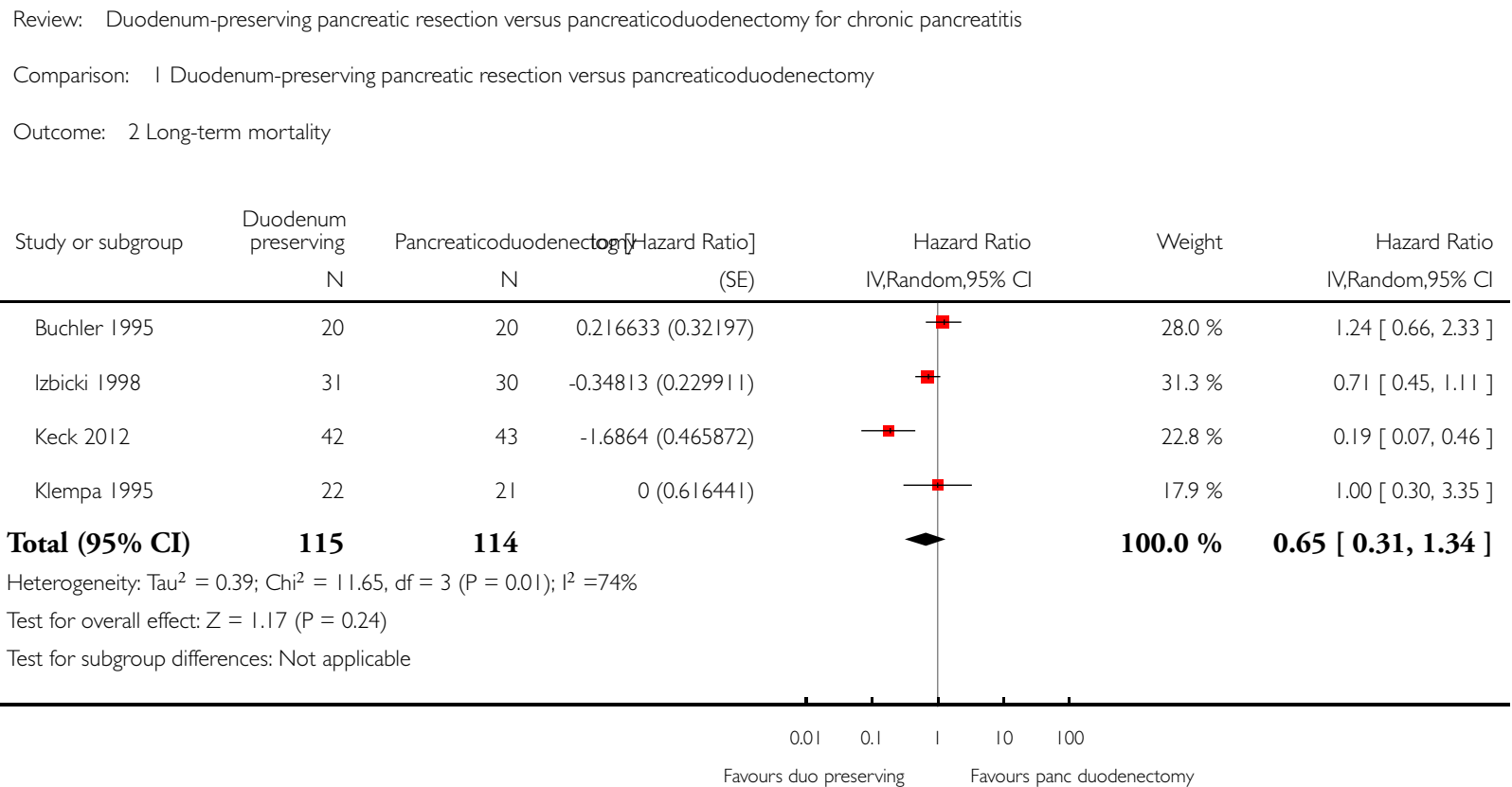

\section{Analysis I.3. Comparison I Duodenum-preserving pancreatic resection versus pancreaticoduodenectomy, Outcome 3 Quality of life ( 3 months to 5 years).}

Quality of life (3 months to 5 years)

\begin{tabular}{|l|l|l|l|l|}
\hline Study & $\begin{array}{l}\text { Quality of life scale used } \\
\text { and time of measurement }\end{array}$ & $\begin{array}{l}\text { Median score in duode- } \\
\text { num preserving pancre- } \\
\text { atic resection group }\end{array}$ & $\begin{array}{l}\text { Se- } \\
\text { dian score in pancreatico- } \\
\text { duodenectomy group }\end{array}$ & Not reported \\
\hline Izbicki 1998 & $\begin{array}{l}\text { EORTC QLQ-C30 global } \\
\text { health status (higher scores } \\
\text { indicate better quality of } \\
\text { life); median follow-up } 24 \\
\text { months (range } 12 \text { months } \\
\text { to 36 months) }\end{array}$ & 28.7 & 67 & P \\
\hline Keck 2012 & $\begin{array}{l}\text { EORTC QLQ-C30 global } \\
\text { health status (higher scores } \\
\text { indicate better quality of } \\
\text { life); median follow-up } 41 \\
\text { months (range 3 months to } \\
80 \text { months) }\end{array}$ & 67 & \\
\hline
\end{tabular}




\section{Analysis I.4. Comparison I Duodenum-preserving pancreatic resection versus pancreaticoduodenectomy,}

Outcome 4 Quality of life (> 5 years).

Review: Duodenum-preserving pancreatic resection versus pancreaticoduodenectomy for chronic pancreatitis

Comparison: I Duodenum-preserving pancreatic resection versus pancreaticoduodenectomy

Outcome: 4 Quality of life (> 5 years)

\begin{tabular}{|c|c|c|c|c|c|c|c|c|c|c|}
\hline \multirow[t]{2}{*}{ Study or subgroup } & $\begin{array}{l}\text { Duodenum } \\
\text { preserving }\end{array}$ & \multicolumn{4}{|c|}{ Pancreaticoduodenectomy } & \multicolumn{2}{|c|}{$\begin{array}{r}\text { Mean } \\
\text { Difference }\end{array}$} & & \multirow[t]{2}{*}{ Weight } & \multirow{2}{*}{$\begin{array}{r}\text { Mean } \\
\text { Difference } \\
\text { IV,Fixed,95\% Cl }\end{array}$} \\
\hline & N & Mean(SD) & N & Mean(SD) & & & $\mathrm{ked}, 95 \% \mathrm{Cl}$ & & & \\
\hline Buchler 1995 & 20 & $65(22.3)$ & 20 & $58.3(34.2)$ & & & 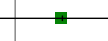 & $\longrightarrow$ & $23.8 \%$ & $6.70[-11.19,24.59]$ \\
\hline Izbicki 1998 & 31 & $67(19.9)$ & 30 & $58(19.9)$ & & & & & $76.2 \%$ & $9.00[-0.99,18.99]$ \\
\hline Total $(95 \% \mathrm{CI})$ & 51 & & 50 & & & & & & $100.0 \%$ & $8.45[-0.27,17.18]$ \\
\hline \multicolumn{11}{|c|}{ Heterogeneity: $\mathrm{Chi}^{2}=0.05, \mathrm{df}=\mathrm{I}(\mathrm{P}=0.83) ; \mathrm{I}^{2}=0.0 \%$} \\
\hline \multicolumn{11}{|c|}{ Test for overall effect: $Z=1.90(P=0.057)$} \\
\hline \multicolumn{11}{|c|}{ Test for subgroup differences: Not applicable } \\
\hline & & & & & -20 & -10 & 10 & 20 & & \\
\hline & & & & Favours pan & duod & ectomy & Favou & & serving & \\
\hline
\end{tabular}

Analysis I.5. Comparison I Duodenum-preserving pancreatic resection versus pancreaticoduodenectomy, Outcome 5 Adverse events (proportion).

Review: Duodenum-preserving pancreatic resection versus pancreaticoduodenectomy for chronic pancreatitis

Comparison: I Duodenum-preserving pancreatic resection versus pancreaticoduodenectomy

Outcome: 5 Adverse events (proportion)

\begin{tabular}{|c|c|c|c|c|c|}
\hline Study or subgroup & $\begin{array}{r}\text { Duodenum } \\
\text { preserving } \\
\mathrm{n} / \mathrm{N}\end{array}$ & $\begin{array}{l}\text { Pancreaticoduodenectomy } \\
\text { n/N }\end{array}$ & $\begin{array}{c}\text { Risk Ratio } \\
\text { M- } \\
\text { H,Random,95\% } \\
\text { Cl }\end{array}$ & Weight & $\begin{array}{c}\text { Risk Ratio } \\
\text { M- } \\
\text { H,Random,95\% } \\
\text { Cl }\end{array}$ \\
\hline Buchler 1995 & $3 / 20$ & $4 / 20$ & $\longrightarrow$ & $22.0 \%$ & $0.75[0.19,2.93]$ \\
\hline Farkas 2006 & $0 / 20$ & $8 / 20$ & - & $8.5 \%$ & $0.06[0.00,0.96]$ \\
\hline Izbicki 1998 & $6 / 31$ & $16 / 30$ & - & $33.0 \%$ & $0.36[0.16,0.80]$ \\
\hline Keck 2012 & $14 / 42$ & $13 / 43$ & & $36.5 \%$ & $1.10[0.59,2.06]$ \\
\hline
\end{tabular}

Total (95\% CI)

113

113

$100.0 \%$

$0.55[0.22,1.35]$

Total events: 23 (Duodenum preserving), 4 I (Pancreaticoduodenectomy)

Heterogeneity: $\mathrm{Tau}^{2}=0.48 ; \mathrm{Ch}^{2}=8.29, \mathrm{df}=3(\mathrm{P}=0.04) ; \mathrm{I}^{2}=64 \%$

Test for overall effect: $Z=1.31(P=0.19)$

Test for subgroup differences: Not applicable

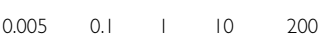

Favours duo preserving Favours panc duodenectomy

Duodenum-preserving pancreatic resection versus pancreaticoduodenectomy for chronic pancreatitis (Review)

Copyright $\odot 2016$ The Cochrane Collaboration. Published by John Wiley \& Sons, Ltd. 


\section{Analysis I.6. Comparison I Duodenum-preserving pancreatic resection versus pancreaticoduodenectomy,}

Outcome 6 Adverse events (number of adverse events).

Review: Duodenum-preserving pancreatic resection versus pancreaticoduodenectomy for chronic pancreatitis

Comparison: I Duodenum-preserving pancreatic resection versus pancreaticoduodenectomy

Outcome: 6 Adverse events (number of adverse events)

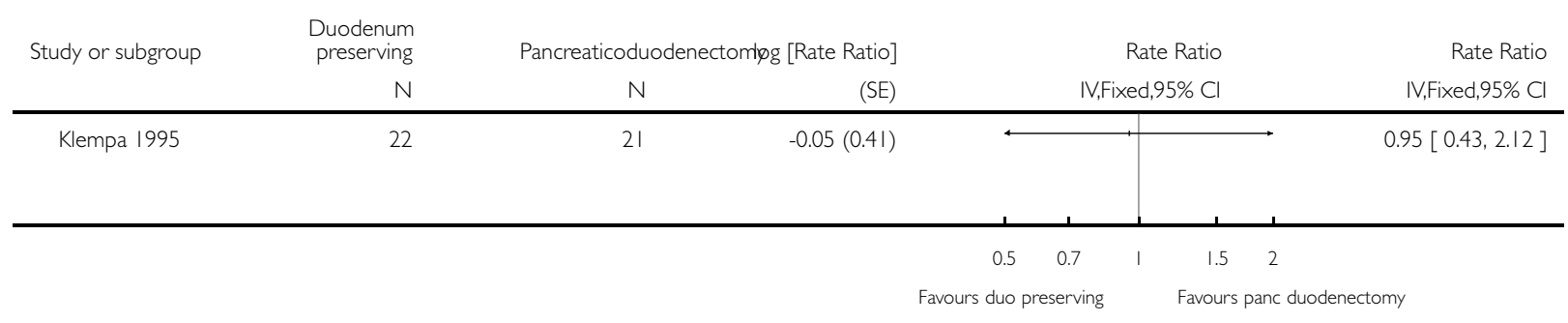

Analysis I.7. Comparison I Duodenum-preserving pancreatic resection versus pancreaticoduodenectomy, Outcome 7 Length of hospital stay.

Length of hospital stay

\begin{tabular}{l|l|l|l|l}
\hline Study & $\begin{array}{l}\text { Mean or median in duo- } \\
\text { denum-preserving } \\
\text { pancreatic head resection } \\
\text { group (days) }\end{array}$ & $\begin{array}{l}\text { Mean } \\
\text { median in pancreatoduo- } \\
\text { denectomy group (days) }\end{array}$ & $\begin{array}{l}\text { Difference in means or } \\
\text { median (days) }\end{array}$ & Statistical significance \\
\hline Buchler 1995 & 13 days (median) & 14 days (median) & -1 days & Not reported \\
\hline Farkas 2006 & 8.5 days (mean) & 13.8 days (mean) & icant) \\
\hline Keck 2012 & 13 days (median) & 14 days (median) & -5.3 days & $\begin{array}{l}\text { P }=0.17 \text { (not statistically signif- } \\
\text { significant) }\end{array}$ \\
\hline Klempa 1995 & 16.5 days (mean) & 21.7 days (mean) & -5.2 days & $\begin{array}{l}\text { P<0.05 (statistically signif- } \\
\text { icant) }\end{array}$ \\
\hline
\end{tabular}

Duodenum-preserving pancreatic resection versus pancreaticoduodenectomy for chronic pancreatitis (Review) 
Analysis I.8. Comparison I Duodenum-preserving pancreatic resection versus pancreaticoduodenectomy, Outcome 8 Employed.

Review: Duodenum-preserving pancreatic resection versus pancreaticoduodenectomy for chronic pancreatitis

Comparison: I Duodenum-preserving pancreatic resection versus pancreaticoduodenectomy

Outcome: 8 Employed

\begin{tabular}{|c|c|c|c|c|c|}
\hline Study or subgroup & $\begin{array}{r}\text { Duodenum } \\
\text { preserving } \\
\text { n/N }\end{array}$ & Pancreaticoduodenectomy & $\begin{array}{c}\text { Risk Ratio } \\
\text { M- } \\
\text { H,Random,95\% } \\
\text { Cl }\end{array}$ & Weight & $\begin{array}{c}\text { Risk Ratio } \\
\text { M- } \\
\text { H,Random,95\% } \\
\text { Cl } \\
\end{array}$ \\
\hline Buchler 1995 & $7 / 15$ & $1 / 14$ & 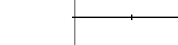 & $4.5 \%$ & $6.53[0.92,46.60]$ \\
\hline Izbicki 1998 & $|1 / 2|$ & $3 / 14$ & $\longrightarrow$ & $12.7 \%$ & $2.44[0.83,7.22]$ \\
\hline Keck 2012 & $32 / 42$ & $27 / 43$ & $\mathbf{B}$ & $49.1 \%$ & $1.21[0.91,1.61]$ \\
\hline Klempa 1995 & $15 / 20$ & $10 / 20$ & $=$ & $33.7 \%$ & $1.50[0.90,2.49]$ \\
\hline Total $(95 \% \mathrm{CI})$ & 98 & 91 & - & $100.0 \%$ & $1.54[1.00,2.37]$ \\
\hline \multicolumn{6}{|c|}{ Total events: 65 (Duodenum preserving), 4I (Pancreaticoduodenectomy) } \\
\hline \multicolumn{6}{|c|}{ Heterogeneity: $\mathrm{Tau}^{2}=0.08 ; \mathrm{Chi}^{2}=5.28, \mathrm{df}=3(\mathrm{P}=0.15) ; \mathrm{I}^{2}=43 \%$} \\
\hline \multicolumn{6}{|c|}{ Test for overall effect: $Z=1.95(P=0.05 \mathrm{I})$} \\
\hline \multicolumn{6}{|c|}{ Test for subgroup differences: Not applicable } \\
\hline
\end{tabular}


Analysis I.9. Comparison I Duodenum-preserving pancreatic resection versus pancreaticoduodenectomy, Outcome 9 New-onset diabetes.

Review: Duodenum-preserving pancreatic resection versus pancreaticoduodenectomy for chronic pancreatitis

Comparison: I Duodenum-preserving pancreatic resection versus pancreaticoduodenectomy

Outcome: 9 New-onset diabetes

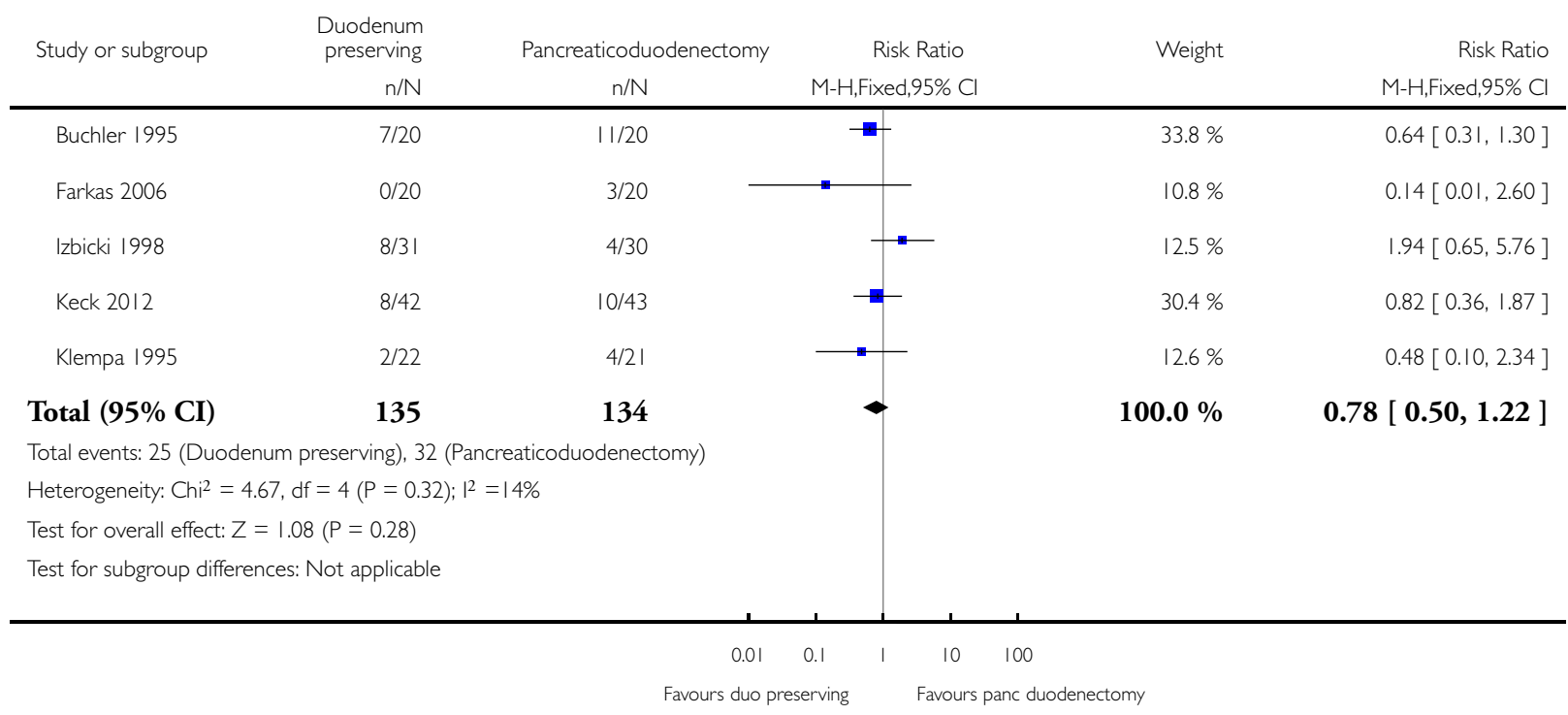


Analysis I.I0. Comparison I Duodenum-preserving pancreatic resection versus pancreaticoduodenectomy, Outcome 10 Pancreatic exocrine insufficiency.

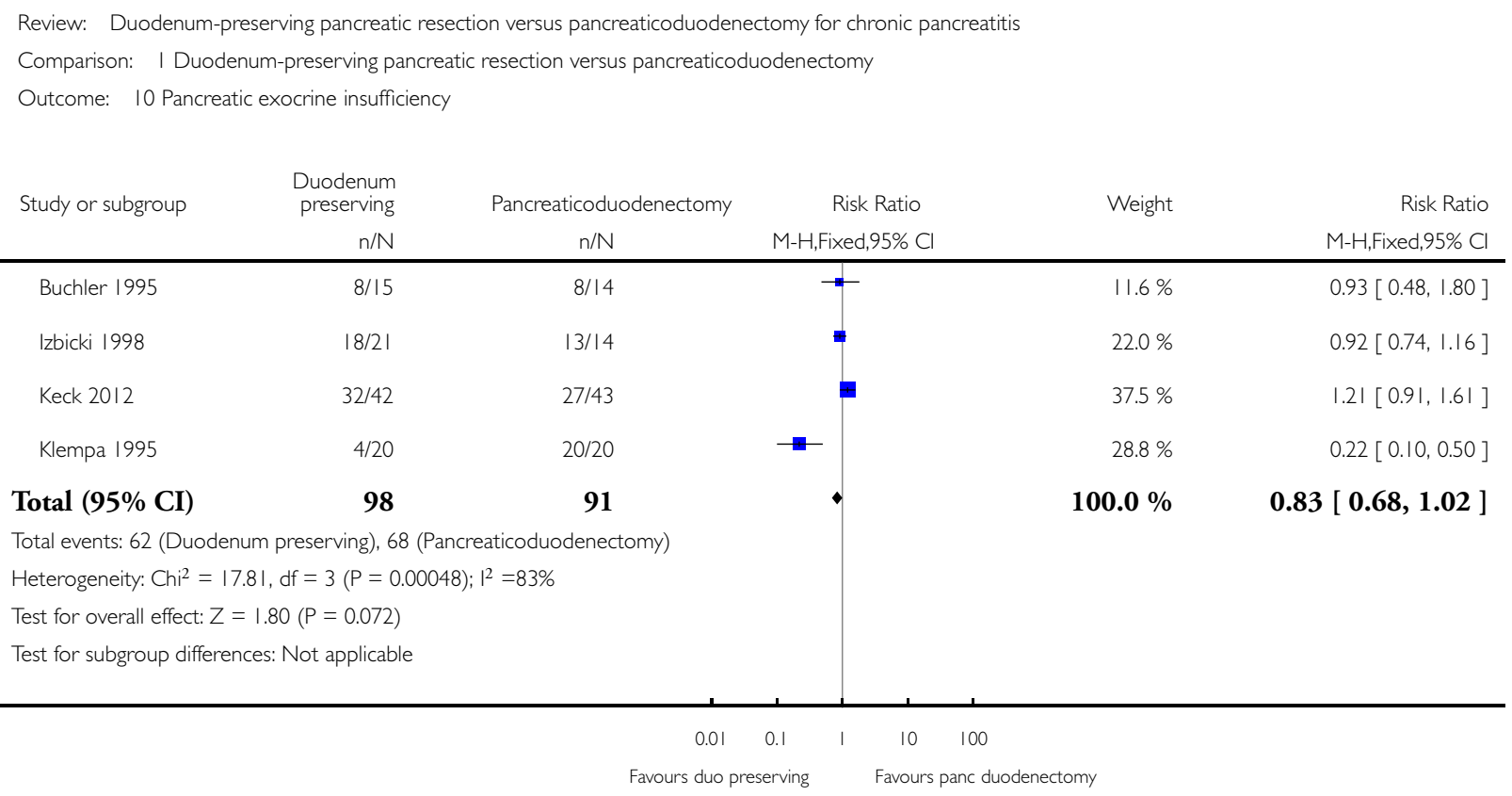


Analysis 2.I. Comparison 2 Duodenum-preserving pancreatic resection versus pancreaticoduodenectomy (subgroup analysis), Outcome I Short-term mortality.

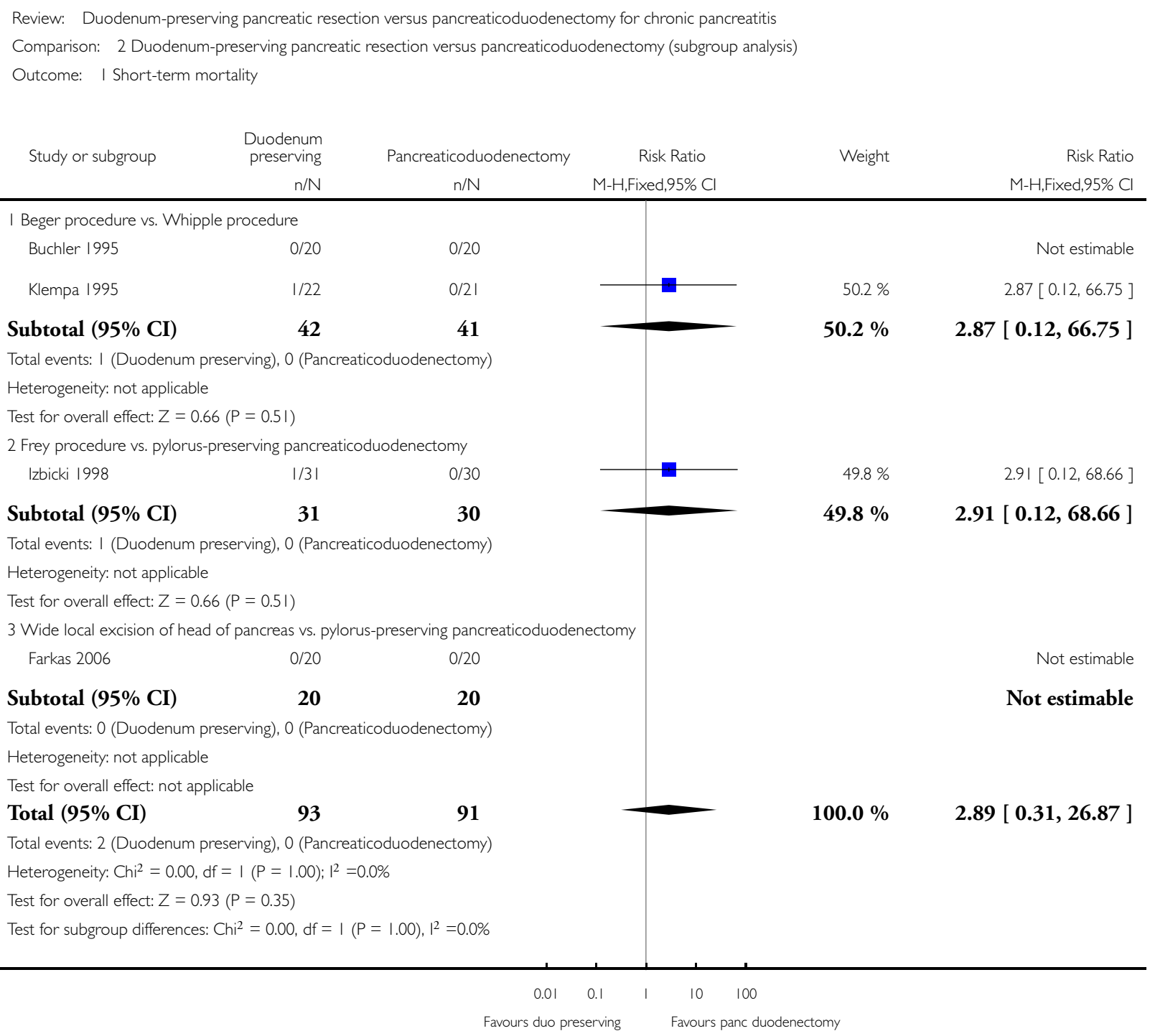


Analysis 2.2. Comparison 2 Duodenum-preserving pancreatic resection versus pancreaticoduodenectomy (subgroup analysis), Outcome 2 Long-term mortality.

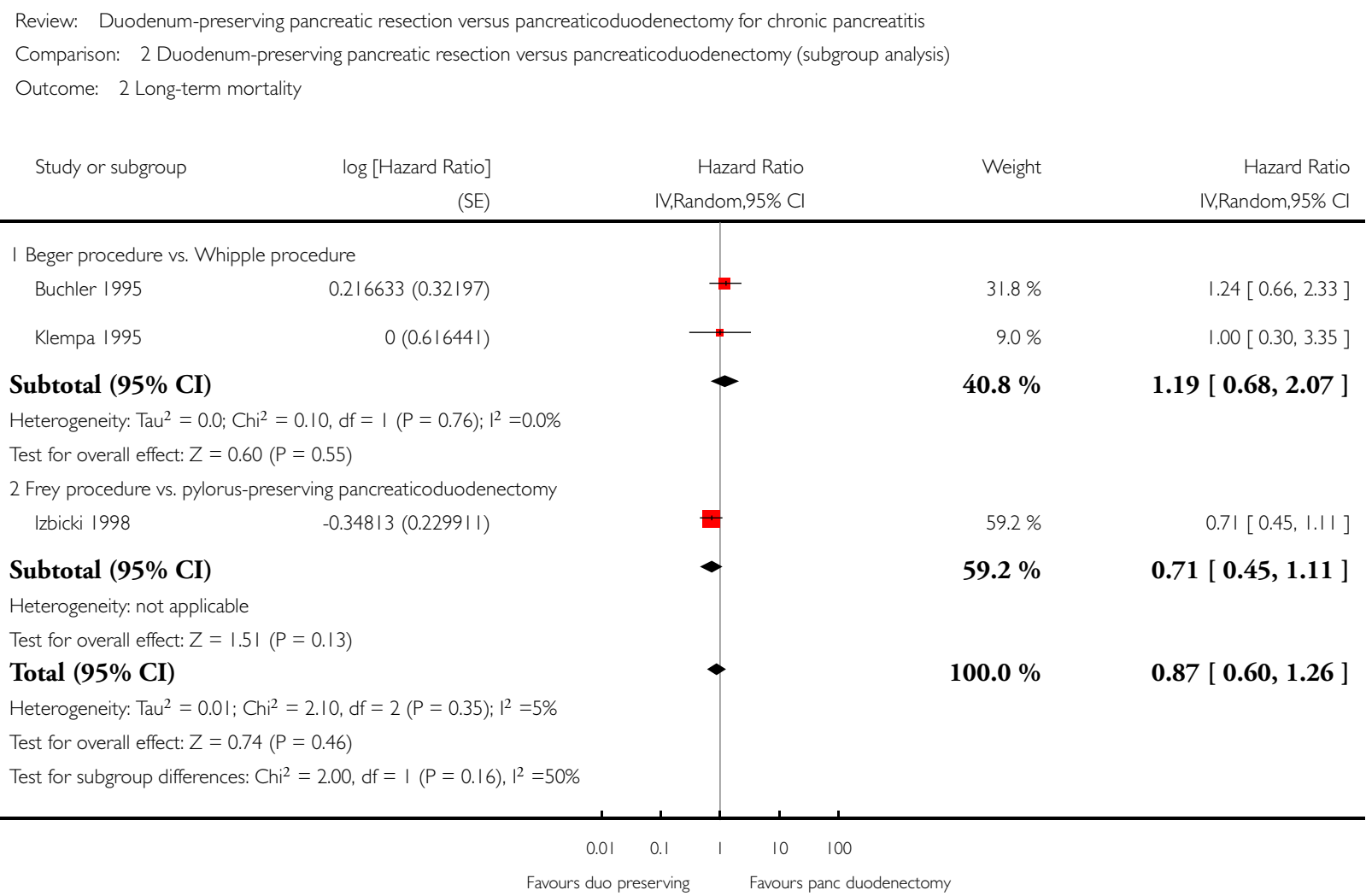

\section{Analysis 2.3. Comparison 2 Duodenum-preserving pancreatic resection versus pancreaticoduodenectomy} (subgroup analysis), Outcome 3 Quality of life (3 months to I year).

Quality of life (3 months to 1 year)

Study

Quality of life scale used Median score in duode- MeStatistical significance and time of measurement num preserving pancreatic resection group dian score in pancreaticoduodenectomy group

Frey procedure vs. pylorus-preserving pancreaticoduodenectomy

\begin{tabular}{|c|c|c|c|c|}
\hline Izbicki 1998 & $\begin{array}{l}\text { EORTC QLQ-C30 global } \\
\text { health status (higher scores } \\
\text { indicate better quality of } \\
\text { life); median follow-up } 24 \\
\text { months (range } 12 \text { months } \\
\text { to } 36 \text { months) }\end{array}$ & 85.7 & 28.6 & Not reported \\
\hline
\end{tabular}




\section{Analysis 2.4. Comparison 2 Duodenum-preserving pancreatic resection versus pancreaticoduodenectomy (subgroup analysis), Outcome 4 Quality of life ( $>5$ years).}

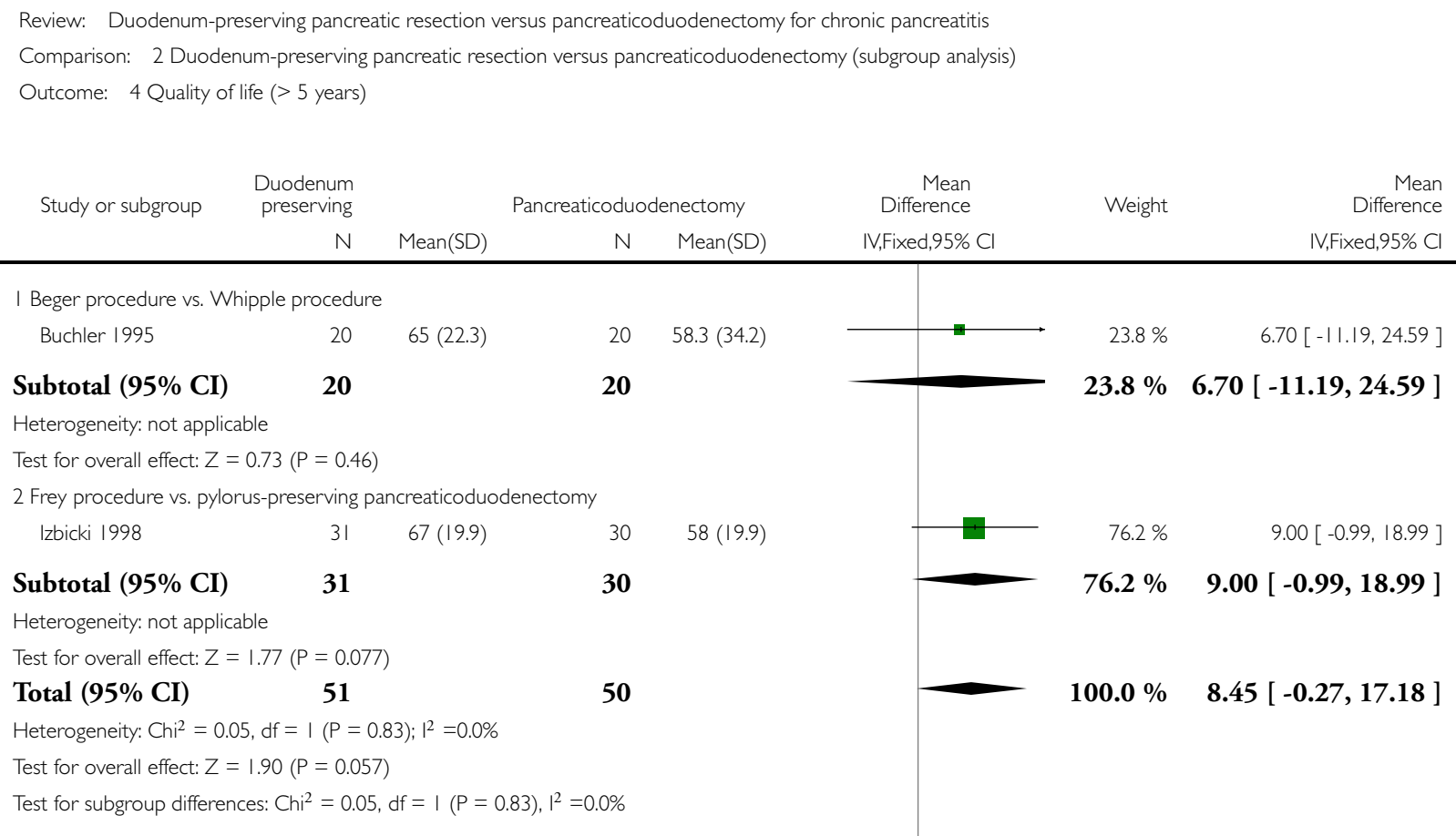

N Mean(SD) N Mean(SD) IV,Fixed,95\% Cl IV,Fixed,95\% Cl

I Beger procedure vs. Whipple procedure

$65(22.3) \quad 20 \quad 58.3(34.2)$

$\longrightarrow \quad 23.8 \%$

$6.70[-11.19,24.59]$

Subtotal (95\% CI)

20

20

Heterogeneity: not applicable

Test for overall effect: $Z=0.73(P=0.46)$

2 Frey procedure vs. pylorus-preserving pancreaticoduodenectomy

$\begin{array}{lllll}\text { Izbicki } 1998 & 31 & 67(19.9) & 30 & 58(19.9)\end{array}$

Subtotal (95\% CI) 31

$31 \quad 30$

Heterogeneity: not applicable

Test for overall effect: $Z=1.77(P=0.077)$

Total (95\% CI)

51

50

30

$23.8 \% 6.70$ [-11.19, 24.59]

Heterogeneity: $\mathrm{Chi}^{2}=0.05, \mathrm{df}=\mathrm{I}(\mathrm{P}=0.83) ; \mathrm{I}^{2}=0.0 \%$

Test for overall effect: $Z=1.90(P=0.057)$

Test for subgroup differences: $\mathrm{Chi}^{2}=0.05, \mathrm{df}=\mathrm{I}(\mathrm{P}=0.83), \mathrm{I}^{2}=0.0 \%$

$\left.\begin{array}{lll}50 & 100.0 \% & 8.45[-0.27,17.18\end{array}\right]$ 
Caerulein: a hormone that has a similar action to cholecystokinin (see below).

Calcifications: calcium deposits in tissue.

CFTR mutation: alteration in the genetic code for a protein called cystic fibrosis transport regulator (CFTR).

Cholecystokinin: a hormone that increases the contractility of the gallbladder thus increasing the flow of bile into the small bowel.

Chronic: long-standing.

Coeliac plexus block: injection of long-acting local anaesthetic into the coeliac plexus, a network of nerves that supply the abdominal organs.

Computed tomography: CT scan. This is performed by taking a series of X-rays using special equipment and processing the images using a computer to obtain a final image.

Diabetes: a lifelong condition that causes a person's blood sugar level to become too high.

Digestive enzyme deficiency: shortage of enzymes that help with digestion by breaking down the food that we eat into substances that can be absorbed from the gut.

Duodenal aspirate: fluid obtained from the upper part of the small intestine usually with a tube inserted into the small intestine through the nose or mouth.

Duodenum: upper part of the small bowel. It conducts digested food from the stomach to the middle part of the small bowel (jejunum). The bile duct and the pancreatic duct conduct the bile and pancreatic juice drain into the duodenum.

Elastase: enzyme that breaks down protein.

Endocrine pancreatic insufficiency: deficiency of hormones secreted from cells in the pancreas, clinically manifesting as diabetes because of insulin deficiency.

Endoscopic retrograde cholangio pancreatography: a diagnostic test that involves the use of an endoscope and X-rays to image the pancreas and biliary system.

Endoscopic ultrasound: an ultrasound scan that is performed using an endoscope.

Enteric: small bowel.

Excised: surgically removed.

Exocrine pancreatic insufficiency: deficiency of pancreatic digestive enzymes.

Fistula: an abnormal or surgically made passage between a hollow or tubular organ and the body surface, or between two hollow or tubular organs.

Flatulence: excessive wind.

Gastro-enteric anastomosis: joining the stomach to the small bowel.

Histopathological examination: examination under microscope.

Hypercalcaemia: high calcium in blood.

Hyperparathyroidism: high parathyroid hormone (a hormone involved in maintaining calcium level) in blood.

Hypertension: high blood pressure.

Idiopathic: cause of disease could not be identified.

Insulin: substance that helps regulate blood sugar.

Jaundice: yellowish discolouration of the whites of the eyes, skin, and inner linings of the mouth caused usually by liver diseases or obstruction to the flow of bile from liver into small bowel.

Jejunum: second part of small bowel.

Mortality: death.

Neural: nerve-related.

Neurolysis: destruction of nerve (in this context, using injection of chemicals such as $100 \%$ alcohol (absolute alcohol) or by heat generated by radiofrequency waves).

Oestrogens: hormones that promote the development and maintenance of female characteristics of the body. Such hormones are also produced artificially for use in oral contraceptives or to treat menopausal and menstrual disorders.

Oxidative damage: (in this context) damage due to oxidation, which releases chemicals that cause damage to tissues.

Pancreatic enzyme supplementation: providing pancreatic enzymes.

Pancreatic pseudocysts: fluid collections in the pancreas or the tissues surrounding the pancreas, surrounded by a well-defined wall and containing only fluid with little or no solid material.

Parenchyma: the essential element of the organ as opposed to the supporting tissue.

Pathogenesis: development of a disease.

Peripancreatic: around the pancreas.

Pregabalin: a medicine used for seizures and for pain, which is considered to be due to excessive nerve stimulation.

Pylorus: part of the stomach that connects the stomach to the duodenum.

Duodenum-preserving pancreatic resection versus pancreaticoduodenectomy for chronic pancreatitis (Review)

Copyright $\Subset 2016$ The Cochrane Collaboration. Published by John Wiley \& Sons, Ltd. 
Renal: kidney.

Secretin-enhanced magnetic resonance cholangiopancreatography: a magnetic resonance scan (MRI) done after administering secretin (a hormone that regulates the secretion of the stomach and pancreas).

Sensory fibres: nerve fibres that carry the sensations including pain.

Somatostatin analogue: a chemical with similar action to somatostatin, which is a hormone that decreases stomach and pancreatic secretions.

SPINK 1 mutation: alteration in the genetic code for a protein called serine protease inhibitor Kazal-type 1 (SPINK 1).

Steatorrhoea: bulky, foul-smelling stools due to the presence of excessive fat in the stools.

Stenosis: narrowing.

Surgical excision: surgical removal.

Sympathetic fibres: nerve fibres that control involuntary actions in the body such as control of blood pressure.

Thiazide: a medicine used to lower blood pressure by increasing the excretion of salt and water from body.

Valproate: a medicine used in people with epilepsy.

Visual analogue scale: (in this context) a measurement tool to compare subjective measures such as pain that cannot be directly measured; the respondents specify their pain level along a continuous line between 0 and 10 or 0 and 100 .

\section{Appendix 2. CENTRAL search strategy}

\#1 MeSH descriptor: [Pancreatitis, Chronic] explode all trees

\#2 chronic pancreatitis

\#3 \#1 or \#2

\#4 MeSH descriptor: [Pancreaticoduodenectomy] explode all trees

\#5 MeSH descriptor: [Pancreatectomy] explode all trees

\#6 pancreaticoduodenectomy or pancreaticoduodenectomies or duodenopancreatectomy or duodenopancreatectomies or pancreatectomy

$\# 7 \# 4$ or $\# 5$ or \#6

$\# 8$ \#3 and \#7

\section{Appendix 3. MEDLINE search strategy}

1. randomized controlled trial.pt.

2. controlled clinical trial.pt.

3. randomized.ab.

4. placebo.ab.

5. drug therapy.fs.

6. randomly.ab.

7. trial.ab.

8. groups.ab.

9. 1 or 2 or 3 or 4 or 5 or 6 or 7 or 8

10. exp animals/ not humans.sh.

11. 9 not 10

12. exp Pancreatitis, Chronic/

13. chronic pancreatitis.mp.

14. 12 or 13

15. exp Pancreaticoduodenectomy/

16. exp Pancreatectomy/

17. (pancreaticoduodenectomy or pancreaticoduodenectomies or duodenopancreatectomy or duodenopancreatectomies or pancreatectomy).mp.

18. 15 or 16 or 17

19. 11 and 14 and 18

Duodenum-preserving pancreatic resection versus pancreaticoduodenectomy for chronic pancreatitis (Review) 


\section{Appendix 4. EMBASE search strategy}

1. Clinical trial/

2. Randomized controlled trial/

3. Randomization/

4. Single-Blind Method/

5. Double-Blind Method/

6. Cross-Over Studies/

7. Random Allocation/

8. Placebo/

9. Randomi?ed controlled trial*.tw.

10. Rct.tw.

11. Random allocation.tw.

12. Randomly allocated.tw.

13. Allocated randomly.tw.

14. (allocated adj2 random).tw.

15. Single blind*.tw.

16. Double blind*.tw.

17. ((treble or triple) adj blind*).tw.

18. Placebo*.tw.

19. Prospective study/

20. or/1-19

21. Case study/

22. Case report.tw.

23. Abstract report/ or letter/

24. or/21-23

25. 20 not 24

26. exp Pancreatitis, Chronicl

27. chronic pancreatitis.mp.

28. 26 or 27

29. exp pancreaticoduodenectomy/

30. exp pancreas resection/

31. (pancreaticoduodenectomy or pancreaticoduodenectomies or duodenopancreatectomy or duodenopancreatectomies or pancreatectomy).mp.

32. 29 or 30 or 31

33.25 and 28 and 32

\section{Appendix 5. Science Citation Index search strategy}

\# $1 \mathrm{TS}=$ (chronic pancreatitis)

\# 2 TS=(pancreaticoduodenectomy or pancreaticoduodenectomies or duodenopancreatectomy or duodenopancreatectomies or pancreatectomy)

\# 3 TS=(random* OR rct* OR crossover OR masked OR blind* OR placebo* OR meta-analysis OR systematic review* OR metaanalys*)

\# 4 \#3 AND \#2 AND \#1

Duodenum-preserving pancreatic resection versus pancreaticoduodenectomy for chronic pancreatitis (Review) 


\section{Appendix 6. ClinicalTrials.gov search strategy}

Interventional Studies | chronic pancreatitis | pancreaticoduodenectomy | Phase 2, 3, 4

\section{Appendix 7. WHO ICTRP search strategy}

chronic pancreatitis AND pancreaticoduodenectomy

\section{CONTRIBUTIONSOFAUTHORS}

Conceiving the review: KG.

Designing the review: KG.

Co-ordinating the review: $\mathrm{KG}$.

Designing search strategies: KG.

Study selection: KG, CL, CH.

Data extraction: KG, CL.

Writing the review: KG.

Providing general advice on the review: BRD.

Securing funding for the review: KG.

Performing previous work that was the foundation of the current study: KG.

\section{DECLARATIONSOF INTEREST}

This report is independent research funded by the National Institute for Health Research (NIHR Cochrane Programme Grants, 13/ 89/03 - evidence-based diagnosis and management of upper digestive, hepato-biliary, and pancreatic disorders). The views expressed in this publication are those of the author(s) and not necessarily those of the National Health Service (NHS), the National Institute for Health Research, or the Department of Health.

KG: none known.

CL: none known.

$\mathrm{CH}$ : none known.

BRD: none known.

\section{SOURCES OF SUPPORT}




\section{Internal sources}

- University College London, UK.

\section{External sources}

- National Institute for Health Research, UK.

This project was supported by the National Institute for Health Research, via Cochrane Programme Grant to the CHBG and UGPD groups. The views and opinions expressed therein are those of the authors and do not necessarily reflect those of the Systematic Reviews Programme, NIHR, NHS or the Department of Health.

\section{DIFFERENCES BETWEEN PROTOCOLANDREVIEW}

1. We added long-term mortality to the list of primary outcomes. Although we anticipated only short-term differences between the treatments compared, we recognised that the interventions may have long-term effects on mortality as well. Clearly, this is an important patient-oriented outcome.

2. We added proportion of people at work at maximal follow-up to the list of secondary outcomes. Although we anticipated only short-term differences between the treatments compared in terms of return to work, we recognised that the interventions may have long-term effects on the ability to work as well. Clearly, this is an important patient-oriented outcome. 